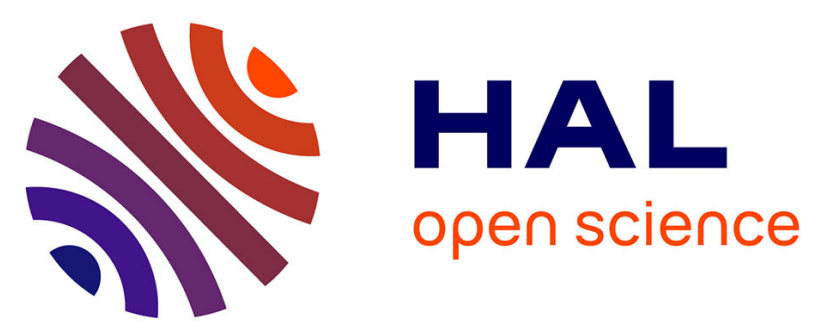

\title{
Lysine production from the sugar alcohol mannitol: Design of the cell factory Corynebacterium glutamicum SEA-3 through integrated analysis and engineering of metabolic pathway fluxes
}

Sarah Lisa Hoffmann, Lukas Jungmann, Sarah Schiefelbein, Lindsay Peyriga, Edern Cahoreau, Jean-Charles Portais, Judith Becker, Christoph Wittmann

\section{To cite this version:}

Sarah Lisa Hoffmann, Lukas Jungmann, Sarah Schiefelbein, Lindsay Peyriga, Edern Cahoreau, et al.. Lysine production from the sugar alcohol mannitol: Design of the cell factory Corynebacterium glutamicum SEA-3 through integrated analysis and engineering of metabolic pathway fluxes. Metabolic Engineering, 2018, 10.1016/j.ymben.2018.04.019 . hal-01886463

\section{HAL Id: hal-01886463 https://hal.science/hal-01886463}

Submitted on 26 May 2020

HAL is a multi-disciplinary open access archive for the deposit and dissemination of scientific research documents, whether they are published or not. The documents may come from teaching and research institutions in France or abroad, or from public or private research centers.
L'archive ouverte pluridisciplinaire HAL, est destinée au dépôt et à la diffusion de documents scientifiques de niveau recherche, publiés ou non, émanant des établissements d'enseignement et de recherche français ou étrangers, des laboratoires publics ou privés. 


\title{
Author's Accepted Manuscript
}

Lysine production from the sugar alcohol mannitol: Design of the cell factory Corynebacterium glutamicum SEA-3 through integrated analysis and engineering of metabolic pathway fluxes

Sarah Lisa Hoffmann, Lukas Jungmann, Sarah Schiefelbein, Lindsay Peyriga, Edern Cahoreau, Jean-Charles Portais, Judith Becker, Christoph

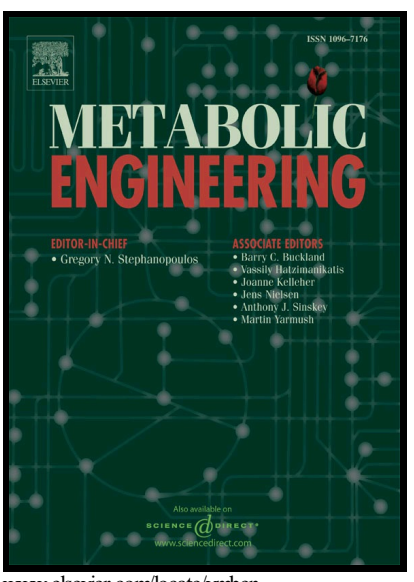
Wittmann

\author{
PII: $\quad$ S1096-7176(18)30072-7 \\ DOI: $\quad$ https://doi.org/10.1016/j.ymben.2018.04.019 \\ Reference: YMBEN1394
}

To appear in: Metabolic Engineering

Received date: 16 February 2018

Revised date: 9 April 2018

Accepted date: 24 April 2018

Cite this article as: Sarah Lisa Hoffmann, Lukas Jungmann, Sarah Schiefelbein, Lindsay Peyriga, Edern Cahoreau, Jean-Charles Portais, Judith Becker and Christoph Wittmann, Lysine production from the sugar alcohol mannitol: Design of the cell factory Corynebacterium glutamicum SEA-3 through integrated analysis and engineering of metabolic pathway fluxes, Metabolic Engineering, https://doi.org/10.1016/j.ymben.2018.04.019

This is a PDF file of an unedited manuscript that has been accepted for publication. As a service to our customers we are providing this early version of the manuscript. The manuscript will undergo copyediting, typesetting, and review of the resulting galley proof before it is published in its final citable form. Please note that during the production process errors may be discovered which could affect the content, and all legal disclaimers that apply to the journal pertain. 
Lysine production from the sugar alcohol mannitol:

Design of the cell factory Corynebacterium glutamicum

SEA-3 through integrated analysis and engineering of metabolic pathway fluxes

Sarah Lisa Hoffmann ${ }^{1}$, Lukas Jungmann ${ }^{1}$, Sarah Schiefelbein ${ }^{1}$, Lindsay Peyriga $^{2,3,4}$, Edern Cahoreau ${ }^{2,3,4}$, Jean-Charles Portais ${ }^{2,3,4}$, Judith Becker ${ }^{1}$, Christoph Wittmann ${ }^{1^{*}}$

${ }^{1}$ Institute of Systems Biotechnology, Saarland University, Germany

${ }^{2}$ Université de Toulouse, INSA, UPS, INP, Toulouse, France

${ }^{3}$ INRA, UMR792 Ingénierie des Systèmes Biologiques et des Procédés, Toulouse, France

${ }^{4}$ CNRS, UMR5504, Toulouse, France

"Corresponding author. Campus A1.5, 66123 Saarbrücken, Germany, Tel.: +49-681-302-71970; fax: +49-681-302-71972. christoph.wittmann@unisaarland.de

\section{Abstract}

The amino acid lysine is among the world's most important biotechnological products, and enabling its manufacture from the most attractive new materials is an ever-present challenge. In this study, we describe a cell 


\section{ACCEPTED MANUSCRIPT}

factory of Corynebacterium glutamicum, which produces lysine from mannitol. A preliminary mutant obtained by the deletion of the mannitol repressor MtIR in the glucose-based, lysine-producing C. glutamicum produced only small amounts of lysine. This limitation was due to the significant accumulation of fructose and a limited NADPH supply, which caused a low flux of only $6 \%$ into the oxidative pentose phosphate (PP) pathway. Subsequent expression of fructokinase slightly increased production but failed to substantially redirect the flux from the EmdenMeyerhof-Parnas (EMP) pathway to the PP pathway. This suggested the design C. glutamicum SEA-3, which overexpressed the NADPH-dependent glyceraldehyde 3-phosphate dehydrogenase GapN from Streptococcus mutans and coupled the EMP pathway flux to NADPH formation. When grown on mannitol, the SEA-3 strain had a lysine yield of $0.24 \mathrm{~mol} \mathrm{~mol}^{-1}$ and a specific productivity of $1.1 \mathrm{mmol} \mathrm{g}^{-1} \mathrm{~h}^{-1}$, approximately $50 \%$ and $70 \%$ higher, respectively, than those of the basic producer. A computational pathway analysis revealed that this design would potentially enable a lysine yield of $0.9 \mathrm{~mol} \mathrm{~mol}^{-1}$, providing room for further development. Our findings open new avenues for lysine production from marine macroalgae, which is farmed globally as an attractive third-generation renewable resource. Mannitol is a major constituent of these algae (up to $30 \%$ and higher) and can be easily extracted from their biomass with hot water.

Keywords: metabolic flux analysis; ${ }^{13} \mathrm{C}$; elementary flux mode; fructokinase; glyceraldehyde 3-phosphate dehydrogenase; NADPH; lysine; oxidative pentose phosphate pathway; fructose; seaweed; macroalgae; biomass 


\section{Introduction}

The soil bacterium Corynebacterium glutamicum is the dominant industrial producer of lysine. More than 2.5 million tons of this amino acid are produced annually for animal nutrition (Eggeling and Bott, 2015; Wittmann and Becker, 2007) and applications in the pharmaceutical, cosmetic, and polymer industries (Koffas and Stephanopoulos, 2005). Classical breeding and, more recently, systems metabolic engineering approaches have created lysine producers with superior production performance in terms of yield, titer and productivity (Becker et al., 2011). Contemporary lysine production is based on glucose and starch feedstocks in the Western world and on sucrose, raw sugar and molasses in the Eastern world, leading to unfavorable competition with human nutritional needs (Schneider et al., 2011). The need for more sustainable feedstocks appears inevitable because of the growing world population. Promising attempts have employed nonedible second-generation renewables, such as xylose (Buschke et al., 2011; Kawaguchi et al., 2006; Sasaki et al., 2008), cellobiose (Kotrba et al., 2003; Ryu and Karim, 2011; Sasaki et al., 2008), hemicellulose, and cellulose (Ryu and Karim, 2011). However, their production suffers from technical challenges in upstream raw material processing (Buschke et al., 2013a; Naik et al., 2010; Tan et al., 2008) and from the formation of inhibitory ingredients during pretreatment (Buschke et al., 2013b).

Research has now begun to focus on a third generation of renewables that might be even more efficiently and sustainably produced: marine macroalgae (seaweed), which are an excellent renewable resource (Goh and Lee, 2010). 
Ocean farms are seemingly more sustainable than land-based agriculture because seaweed cultivation requires no fresh water, chemical fertilizer, or land, the need for which is a significant drawback to land-based cultivation (Tiwari and Troy, 2015). Global seaweed production reached 3 million tons dry weight in 2012 and is projected to reach 500 million tons by 2050 (Rasmus et al., 2016). Individual strands of seaweed can grow up to $60 \mathrm{~cm}$ per day, which is the fastest linear growth on earth, ultimately reaching heights of 50 meters and more.

Mannitol is a major constituent of macroalgae. This sugar alcohol constitutes up to $30 \%$ of dried seaweed, can be easily extracted using hot water, and has attracted immense interest as a bio-based raw material (Iwamoto and Shiraiwa, 2005). C. glutamicum does not use mannitol naturally, although a catabolic operon is encoded in the genome (Becker et al., 2016), because the bacterium constitutively expresses the repressor protein MtIR that prevents expression of the two structural genes $m t / T$ and $m t I D$, which encode a transporter of the major facilitator superfamily (MFS) and NAD-dependent mannitol dehydrogenase, respectively (Peng et al., 2011) (Fig. 1A). Accordingly, the mannitol catabolic pathway is inactive, even when mannitol is the sole carbon source. Deletion of the $m t / R$ gene enables the transcription of $m t / T$ and $m t I D$ and subsequent mannitol utilization (Peng et al., 2011). The metabolism of fructose, the product of mannitol oxidation, involves fructose efflux by a currently unassigned transporter and reuptake by the fructosespecific PTS (Moon et al., 2005; Moon et al., 2007) (Fig. 1B).

In this study, we report the first metabolically engineered C. glutamicum strain capable of producing lysine from mannitol. The hyperproducer $C$. 


\section{ACCEPTED MANUSCRIIPT}

glutamicum LYS-12, recently designed to derive lysine from glucose (Becker et al., 2011), was re-engineered to use mannitol instead. The strain design was supported by $a{ }^{13} \mathrm{C}$ metabolic flux analysis and computational flux modeling, which facilitated exploration of the practically unstudied physiology of mannitol-grown C. glutamicum along the constructed strain genealogy.

\section{Materials and Methods}

\subsection{Strains and plasmids}

The lysine producer C. glutamicum LYS-12 came from a previous study (Becker et al., 2011). Escherichia coli DH5a (Invitrogen, Carlsbad, CA, USA) was used as the host for plasmid amplification. The DNA of Clostridium acetobutylicum ATCC 824 (GenBank Accession No. NC_003030) and of E. coli K12-MG1655 (GenBank Accession No. NC_000913.3) was obtained from the DSMZ (Braunschweig, Germany). The constructed plasmids were adapted to the methylation pattern of $C$. glutamicum using the coexpression of DNA-methyltransferase in the cloning host E. coli NM522 (Invitrogen, Carlsbad, CA, USA) (Becker et al., 2011). The integrative plasmid pClik int $\operatorname{sac} B$ was used for the genomic modification of $C$. glutamicum (Becker et al., 2005). The vector contained a multiple cloning site, origins of replication for E. coli and C. glutamicum, as well as the kanamycin resistance gene $k_{a n}{ }^{R}$ and the sacB gene from Bacillus subtilis, which encodes levansucrase, as selection markers (Becker et al., 2005). In addition, the genes of interest were overexpressed using the episomal plasmid pClik 5a (Buschke et al., 2011), which contained a multiple cloning site, origins of replication for $E$. coli 


\section{ACCEPTED MANUSCRIPT}

and $C$. glutamicum and the kanamycin resistance gene $\mathrm{kan}^{R}$. All strains were maintained as glycerol stocks at $-80^{\circ} \mathrm{C}$. All the strains and plasmids used in this study are listed in Table 1.

\subsection{Genetic engineering}

The construction, purification, and analysis of the plasmid DNA was performed as previously described (Rohles et al., 2016). The genomic modification of C. glutamicum was conducted using homologous recombination and two-step selection (Becker et al., 2005). Briefly, the DNA fragments of interest for genetic modification were amplified from the genomic DNA by PCR (Phusion Flash PCR Master Mix, Thermo Fisher Scientific, St. Leon-Roth, Germany) using sequence-specific primers (Table S1). For plasmid construction, the vector backbone was first linearized using restriction with Smal (FastDigest, Thermo Fisher Scientific). Subsequently, the linearized vector and the fragments of interest were assembled in vitro (Gibson et al., 2009). A 705 bp construct for the deletion of the $m t / R$ gene (NCgl0110) comprised two homologous recombination sequences from the upstream (405 bp) and downstream regions of the target gene (300 bp). The latter contained the terminal end (100 bp) of the coding sequence of the $m t / R$ gene. Two constructs were assembled to express fructokinase in $C$. glutamicum. The first construct contained upstream (540 bp) and downstream (560 bp) flanking sequences as homologous recombination sites, the scrk gene from $C$. acetobutylicum (951 bp), and the sod promotor (192 bp) for constitutive overexpression (Becker et al., 2007). The flanking regions were homologous to the crtEb gene (NCgl0594), which encodes 


\section{ACCEPTED MANUSCRIPT}

lycopene elongase (Heider et al., 2012), as the selected integration site. The second construct contained the abovementioned flanking sequences, the sod promotor, and the mak gene from E. coli (909 bp). The translational start codon of the mak gene (GTG) was replaced by the variant ATG, which promotes translational efficiency (Becker et al., 2010). The constructed plasmids were transformed by heat shock into $E$. coli, multiplied in the cloning host, isolated (HiSpeed Plasmid Midi Prep Kit, GE Healthcare, Munich, Germany), and then transformed into C. glutamicum using electroporation (Becker et al., 2010). The correctness of each strain and plasmid was verified by PCR and sequence analysis (GATC Biotech AG, Konstanz, Germany).

\subsection{Media}

The cultivation of $C$. glutamicum included two precultures followed by the main culture. The first preculture was conducted in complex medium containing $37 \mathrm{~g} \mathrm{~L}^{-1} \mathrm{BHI}$ (Brain Heart Infusion, Becton Dickinson, Heidelberg, Germany). Solid BHI medium was prepared by adding $25 \mathrm{~g} \mathrm{~L}^{-1}$ agar (Becton Dickinson). The second preculture and the main culture were conducted in a mineral salt medium that contained (per liter): $10 \mathrm{~g}$ of mannitol, $15 \mathrm{~g}$ of $\left(\mathrm{NH}_{4}\right)_{2} \mathrm{SO}_{4}, 1 \mathrm{~g}$ of $\mathrm{NaCl}, 0.2 \mathrm{~g}$ of $\mathrm{MgSO}_{4} \cdot 7 \mathrm{H}_{2} \mathrm{O}, 55 \mathrm{mg}$ of $\mathrm{CaCl}_{2}, 20 \mathrm{mg}$ of $\mathrm{FeSO}_{4} \cdot 7 \mathrm{H}_{2} \mathrm{O}, 0.5 \mathrm{mg}$ of biotin, $1 \mathrm{mg}$ of thiamin $\cdot \mathrm{HCl}, 1 \mathrm{mg}$ of calcium pantothenate, $100 \mathrm{~mL}$ of buffer solution (2 M potassium phosphate, $\mathrm{pH} 7.8$ ), $10 \mathrm{~mL}$ of trace element solution $\left(200 \mathrm{mg} \mathrm{L}^{-1} \mathrm{FeCl}_{3} \cdot 6 \mathrm{H}_{2} \mathrm{O}, 200 \mathrm{mg} \mathrm{L}^{-1}\right.$ $\mathrm{MnSO}_{4} \cdot \mathrm{H}_{2} \mathrm{O}, 50 \mathrm{mg} \mathrm{L}^{-1} \mathrm{ZnSO}_{4} \cdot 7 \mathrm{H}_{2} \mathrm{O}, 20 \mathrm{mg} \mathrm{L}^{-1} \mathrm{CuCl}_{2} \cdot 2 \mathrm{H}_{2} \mathrm{O}, 20 \mathrm{mg} \mathrm{L}^{-1}$ $\mathrm{Na}_{2} \mathrm{~B}_{4} \mathrm{O}_{7} \cdot 10 \mathrm{H}_{2} \mathrm{O}, 10 \mathrm{mg} \mathrm{L}^{-1}\left(\mathrm{NH}_{4}\right)_{6} \mathrm{Mo}_{7} \mathrm{O}_{24} \cdot 4 \mathrm{H}_{2} \mathrm{O}$, adjusted to $\mathrm{pH} 1$ with $\left.\mathrm{HCl}\right)$, 


\section{ACCEPTED MANUSCRIPT}

and $1 \mathrm{~mL}$ of chelating agent solution (30 mg of 3,4-dihydroxybenzoic acid with $50 \mu \mathrm{L}$ of $6 \mathrm{M} \mathrm{NaOH}$ ). For isotopic tracer studies, the naturally labeled mannitol was replaced by $99 \%\left[1{ }^{13} \mathrm{C}\right]$ mannitol (Omicron Biochemicals, South Bend, IN, USA). Selected isotope experiments were conducted using $99 \%\left[1-{ }^{13} \mathrm{C}\right]$ glucose and $99 \%\left[1-{ }^{13} \mathrm{C}\right]$ fructose (Omicron Biochemicals). For the cultivation of strains that harbored episomal plasmids, kanamycin was added to the medium to a final concentration of $50 \mu \mathrm{g} \mathrm{mL}^{-1}$.

\subsection{Batch cultivation in shake flasks}

C. glutamicum was cultivated in baffled shake flasks filled to $10 \%$ with liquid medium. Single colonies from agar plates incubated for $24 \mathrm{~h}$ at $30^{\circ} \mathrm{C}$ were used as the inoculum for the first preculture. After incubation for $10 \mathrm{~h}$, the cells were harvested by centrifugation $\left(5 \mathrm{~min}, 8800 \times \mathrm{g}\right.$, and $\left.30^{\circ} \mathrm{C}\right)$, washed twice with mannitol mineral salt medium and subsequently used as the inoculum for the second preculture. The second preculture was then harvested during the exponential growth phase, treated as described above and used as the inoculum for the main culture. All shake flask cultivations were conducted in triplicate at $30^{\circ} \mathrm{C}$ and $230 \mathrm{rpm}$ on an orbital shaker (Multitron, Infors AG, Bottmingen, Switzerland). Dissolved oxygen was monitored in the shake flask cultures by fluorescence measurement (PreSens, Regensburg, Germany) (Wittmann et al., 2003). The inoculum level in the isotope experiments was kept below $0.1 \%$ of the cell concentration sampled for the ${ }^{13} \mathrm{C}$ labeling analysis; thus, the influence of unlabeled biomass on the subsequent labeling analysis could be neglected (Wittmann, 2007). 


\section{ACCEPTED MANUSCRIPT}

\subsection{Quantification of cell concentration}

The cell concentration was determined by measuring the optical density $\left(\mathrm{OD}_{660}\right)$ at $660 \mathrm{~nm}$ (UV-1600PC spectrophotometer, VWR, Hannover, Germany). The cell dry mass (CDM) was determined gravimetrically. Briefly, $10 \mathrm{~mL}$ of culture broth was centrifuged $\left(10 \mathrm{~min}, 9800 \times \mathrm{g}, 4^{\circ} \mathrm{C}\right)$, and the collected cells were washed three times with deionized water and dried at $80^{\circ} \mathrm{C}$ to a constant weight. The correlation factor obtained was CDM [g L $\left.{ }^{1}\right]=0.352 \times \mathrm{OD}_{660}$. All measurements were conducted in triplicate.

\subsection{Quantification of substrates and products}

For the quantification of amino acids, the culture supernatant was diluted 1:10 with $\alpha$-amino butyric acid as an internal standard and analyzed by HPLC (Krömer et al., 2005). The concentrations of mannitol and fructose were determined by HPLC (1260 Infinity Series, Agilent, Darmstadt, Germany), using a Metacarb $87 \mathrm{C}$ column (300 x $7.8 \mathrm{~mm}$, Agilent), a Metacarb $87 \mathrm{C}$ guard column $(50 \times 7.8 \mathrm{~mm}$, Agilent), a desalting column (Micro-Guard Deashing Cartridge, Bio-Rad, Munich, Germany), and demineralized water as the mobile phase at $85^{\circ} \mathrm{C}$ and a flow rate of $0.5 \mathrm{~mL} \mathrm{~min}^{-1}$. Refraction index measurement was used for detection, and external standards were used for quantification. The quantification of trehalose, lactate, and acetate was performed using isocratic HPLC (1260 Infinity Series, Agilent). The separation was performed on an Aminex HPX-87H column $(300 \times 7.8 \mathrm{~mm}$, Bio-Rad) at $65^{\circ} \mathrm{C}$ using $50 \mathrm{mM} \mathrm{H}_{2} \mathrm{SO}_{4}$ as the mobile phase at a flow rate of 
$0.5 \mathrm{~mL} \mathrm{~min}^{-1}$. Detection was performed via the refraction index, and external standards were used for quantification.

\subsection{GC-MS labeling analysis}

The mass isotopomer distributions (MIDs) of amino acids from the cell protein were determined by gas chromatography-mass spectrometry (GC 7890A, 5975C quadrupole detector, Agilent) (Wittmann et al., 2002). Briefly, cells (approximately $1 \mathrm{mg}$ of CDM) were harvested (5 min, $8800 \times g, 4^{\circ} \mathrm{C}$ ), washed twice with deionized water, and hydrolyzed $\left(6 \mathrm{M} \mathrm{HCl}, 24 \mathrm{~h}, 110^{\circ} \mathrm{C}\right)$ (Wittmann, 2007). Cell debris was removed by filtration $(0.2 \mu \mathrm{m}$, Merck Millipore, Darmstadt, Germany). The hydrolysate was dried under nitrogen, followed by derivatization of the amino acids to $t$-butyldimethylsilyl derivatives with $\quad N$-methyl- $N$-t-butyldimethylsilyl-trifluoroacetamide (MBDSTFA) (Macherey-Nagel, Düren, Germany). A GC/MS analysis of the derivatized amino acids was conducted as previously described (Kiefer et al., 2004). Generally, the samples were first measured in the scan mode to check for potential isobaric interference between the analytes of interest and other sample components. The labeling patterns of the analytes were then determined in duplicate via selective ion monitoring (SIM) of selected ion clusters. The mean experimental error for the mass isotopomer quantification was below $0.5 \%$. All MIDs were corrected for natural isotopes (van Winden et al., 2002). The outputs of the correction were the mass isotopomer fractions of the carbon skeleton of the analytes (MID $\left.D_{\text {corr }}\right)$. The total ${ }^{13} \mathrm{C}$ enrichment of the carbon skeleton of a compound with $n$ carbon atoms, termed summed fractional labeling (SFL) (Christensen et al., 2000), was calculated from the 
corresponding MID according to Equation 1. The SFL data are expressed as

percentages; $100 \%$ represents a fully ${ }^{13} \mathrm{C}$-labeled carbon backbone, and $i$ represents the number of ${ }^{13} \mathrm{C}$ atoms of a given isotopomer.

$$
S F L=\sum_{i=1}^{n+1} \frac{i \cdot M I D_{i, c o r r}}{n} \cdot 100
$$

\subsection{NMR labeling analysis}

Cells (about $50 \mathrm{mg}$ cell dry weight) were hydrolyzed for 12 hours in $2 \mathrm{~mL} \mathrm{HCl}(6 \mathrm{M})$ at $110{ }^{\circ} \mathrm{C}$. The obtained hydrolysate was dried, washed twice in $\mathrm{D}_{2} \mathrm{O}$, and resuspended in $200 \mu \mathrm{D} \mathrm{D}_{2} \mathrm{O}\left(0.1 \% \mathrm{DCl}, 1 \mathrm{mM} \mathrm{TSPd}_{4}\right)$. NMR experiments were then performed at $280.0 \mathrm{~K}$ on a Bruker Avance III spectrometer operating at $800 \mathrm{MHz}$ proton frequency and equipped with a QPCI cryogenic probe head. The isotopic enrichment of the alanine carbons were obtained using a combination of $2 \mathrm{D}$ zeroquantum filtered-TOCSY (ZQF-TOCSY) and $1 \mathrm{D}\left\{{ }^{1} \mathrm{H}\right\}{ }^{13} \mathrm{C}$ with long d1 delay of $30 \mathrm{sec}$ to allow full relaxation of ${ }^{13} \mathrm{C}$ magnetization between scans. Briefly, the proton decoupled ${ }^{13} \mathrm{C}$ NMR provided the relative intensities of ${ }^{13} \mathrm{C}$ carbons only $\left({ }^{12} \mathrm{C}\right.$ were not detectable in direct 13C -NMR carbon experiment). The ZQF-TOCSY then gave access to the partition between ${ }^{12} \mathrm{C}$ - and ${ }^{13} \mathrm{C}$-linked ${ }^{1} \mathrm{H}$ and furthermore to the ${ }^{13} \mathrm{C}$ specific enrichment of protonated carbons $\mathrm{C}_{3}$ and $\mathrm{C}_{2}$ of alanine. The ${ }^{13} \mathrm{C}$ enrichment of the alanine carbons $\mathrm{C}_{1}$ and $\mathrm{C} 2$ was then recalculated from the ${ }^{13} \mathrm{C}$ relative intensities between $C_{1}, C_{2}$ and $C_{3}$ from $1 D{ }^{13} \mathrm{C}$, calibrated from the $C_{3}$ enrichment, measured with ZQF-TOCSY. For each sample, the signal to noise ratio 


\section{ACCEPTED MANUSCRIPT}

(SNR) was measured either with ${ }^{13} \mathrm{C}$ 1D or 2D TOCSY acquisitions. The standard errors of the presented measurements were calculated from the respective SNR.

\subsection{Metabolic modeling and flux estimation}

The aspects of the metabolic network of mannitol-grown C. glutamicum considered in this study comprised mannitol uptake (MtlT), mannitol 2dehydrogenase (MtID) for the conversion of mannitol into fructose, and a fructose-specific phosphotransferase system $\left(\mathrm{PTS}^{\mathrm{Frc}}\right)$ for the phosphorylation of fructose into fructose 1-phosphate (Peng et al., 2011). In addition, the Emden-Meyerhof-Parnas (EMP) pathway, the pentose phosphate (PP) pathway, the tricarboxylic acid (TCA) cycle, anaplerotic carboxylation, the biosynthesis of lysine and other byproducts, and the anabolic pathways from intermediary precursors into biomass were considered (Becker et al., 2011). The metabolic networks of the mutants created in this work additionally contained the implemented reactions, i.e., fructokinase and NADPHdependent glyceraldehyde 3-phosphate dehydrogenase. The ${ }^{13} \mathrm{C}$ labeling information of the proteinogenic amino acids derived from isotope experiments on (i) $\left[1-{ }^{13} \mathrm{C}\right]$ mannitol and (ii) an equimolar mixture of naturally labeled plus $\left[{ }^{13} \mathrm{C}_{6}\right]$ mannitol was found not discriminative to obtain a unique flux optimum of a fully resolved network containing fine structures, such as bidirectional and reversible reactions, via global parameter estimation using OpenFLUX software (Quek et al., 2009) (data not shown). Accordingly, we determined only the net fluxes through the carbon core metabolism using a simplified approach. Briefly, the labeling pattern of proteinogenic alanine from cells grown on $\left[1-{ }^{13} \mathrm{C}\right]$ mannitol provided the relative flux partitioning between 


\section{ACCEPTED MANUSCRIPT}

the oxidative PP pathway and the EMP pathway at the level of G6P dehydrogenase (Table S2, Table S3). The remaining, dependent net fluxes were estimated with OpenFLUX (Quek et al., 2009) using the flux partitioning ratio between the PP and EMP pathways, together with stoichiometric data on substrate uptake, product formation, growth (Table 2) and the composition of $C$. glutamicum cells (Wittmann and De Graaf, 2005) as the inputs. Additional definitions and assumptions for the calculation of (i) mannitol uptake and fructose conversion fluxes (Table S4), (ii) glycolytic fluxes (Table S5, Table S6), (iii) the lumped anaplerotic net flux fueling the TCA cycle (Table S7), (iv) pyruvate dehydrogenase flux (Table S8), (v) TCA cycle fluxes (Table S9, Table S10), and (vi) fluxes to lysine and byproducts (Table 2) are provided in the supplement. The obtained fluxes are expressed as absolute fluxes $\left(\mathrm{mmol} \mathrm{g}^{-1} \mathrm{~h}^{-1}\right)$ and as relative values (\%) normalized to the mannitol uptake rate (100\%). Experiments were also conducted on $\left[1{ }^{13} \mathrm{C}\right]$ fructose and $\left[1-{ }^{13} \mathrm{C}\right]$ glucose for comparison.

\subsection{Determination of enzymatic activity}

Exponentially growing cells were harvested by centrifugation (5 min, $8800 \mathrm{x}$ $\left.g, 4^{\circ} \mathrm{C}\right)$, washed with disruption buffer $(100 \mathrm{mM}$ Tris. $\mathrm{HCl}(\mathrm{pH} 7.8), 10 \mathrm{mM}$ $\mathrm{MgCl}_{2}$, and $0.75 \mathrm{mM}$ dithiothreitol), resuspended to a final concentration of 1 ( $\mathrm{g}$ cell wet mass) $\mathrm{mL}^{-1}$, and transferred to FastPrep-24 vials containing silica beads $(0.1 \mathrm{~mm}$ diameter) (MP Biomedicals, Illkirch-Graffenstaden, France). The cells were then disrupted in a ribolyzer (5500 rpm, $2 x 30 \mathrm{~s}$ with 2 min break on ice, Precellys-24, PeqLab, Hannover, Germany), followed by the preparation of a crude cell extract via centrifugation (5 min, $13000 \times g$, 
and $4^{\circ} \mathrm{C}$ ). Fructokinase was assayed at $30^{\circ} \mathrm{C}$ in $100 \mathrm{mM}$ Tris $\cdot \mathrm{HCl}$ buffer $(10$ $\mathrm{mM} \mathrm{MgCl} 2, \mathrm{pH}$ 7.8) containing $1 \mathrm{mM}$ NADP, $1 \mathrm{U}$ glucose 6-phosphate dehydrogenase, $2 \mathrm{U}$ phosphoglucose isomerase, $2 \mathrm{mM}$ ATP, $2 \mathrm{mM}$ fructose and $25 \mu \mathrm{L}$ of crude cell extract. Glyceraldehyde 3-phosphate dehydrogenase was assayed at $30^{\circ} \mathrm{C}$ as previously described (Crow and Wittenberger, 1979). Briefly, the NAD-dependent activity was analyzed in $100 \mathrm{mM}$ Tris-HCl buffer ( $\mathrm{pH}$ 8.3, $10 \mathrm{mM} \mathrm{MgCl}$ ) containing $10 \mu \mathrm{L}$ of cell extract, $1 \mathrm{mM} \mathrm{NAD \text {, }}$ and $2 \mathrm{mM}$ glyceraldehyde 3-phosphate. The NADP-dependent activity was quantified in $100 \mathrm{mM}$ Tris- $\mathrm{HCl}$ buffer $\left(\mathrm{pH} 8.3,10 \mathrm{mM} \mathrm{MgCl}_{2}\right.$ ) containing $10 \mu \mathrm{L}$ of cell extract, $1 \mathrm{mM} \mathrm{NADP}$, and $2 \mathrm{mM}$ glyceraldehyde 3-phosphate. Negative controls without substrate and without crude extract were included in all experiments. The reactions were monitored via the change in absorbance at $340 \mathrm{~nm}$. The determination of specific enzyme activity involved quantification of the protein content in the crude cell extract (Quick Start Bradford Dye, BioRad) using bovine serum albumin as the calibration standard.

\subsection{Elementary flux mode analysis}

The calculation of the elementary modes for the metabolism of $C$. glutamicum was performed as previously described (Melzer et al., 2009). The cellular composition of C. glutamicum was taken from a previous study (Wittmann and De Graaf, 2005). The metabolic networks used for the different simulation scenarios are provided in the supplement (Table S11, Table S12, Table S13, and Table S14). 


\section{Results}

\subsection{The deletion of the mannitol repressor gene $m t I R$ in the lysine overproducer C. glutamicum LYS-12 enables the production of lysine from mannitol}

To overcome the expected inability of $C$. glutamicum LYS-12 to grow on mannitol as the sole carbon source (Fig. S1), the $m t / R$ gene (NCgl0110), which encodes the mannitol repressor, was deleted from the genome. Positive clones from the second recombination produced the desired PCR product $(700 \mathrm{bp})$, which differed from that of the wild type (1550 bp). After confirmation of the deletion by sequencing, the obtained strain was designated C. glutamicum SEA-1. This strain utilized mannitol as the sole carbon source (Fig. S1). Moreover, the accumulation of lysine from mannitol was observed (Fig. 2). The mutant displayed two distinct growth phases. Mannitol was taken up in the initial, major growth phase of cultivation (phase I), whereby fructose (the pathway intermediate of mannitol catabolism) transiently accumulated and peaked at a concentration of $9 \mathrm{mM}$ after approximately $26 \mathrm{~h}$. Subsequently, the accumulated fructose and the remaining mannitol were consumed until they were fully depleted after $32 \mathrm{~h}$ (phase II). The production characteristics of the two phases were different. Lysine was secreted at a yield of $0.09 \mathrm{~mol} \mathrm{~mol}^{-1}$ during the first phase, whereas lysine was formed at a yield of $0.20 \mathrm{~mol} \mathrm{~mol}^{-1}$ during the second phase (Fig. 2B, C). Additional byproducts (i.e., trehalose, glutamate, glycine, glutamine, alanine, acetate, and lactate) were secreted almost constantly and did not show a pronounced shift in production. The dissolved oxygen level 
remained above $50 \%$ throughout the entire cultivation period, indicating that the growth environment was fully aerobic (Fig. 2A). The overall lysine yield, averaged over the entire cultivation period, was $0.15 \mathrm{~mol} \mathrm{~mol}^{-1}$ (Table 3).

\subsection{Metabolic fluxes in the basic producer C. glutamicum SEA-1}

Next, intracellular fluxes were determined in C. glutamicum SEA-1 during the initial, major growth phase of the strain. This phase lasted for the first $26 \mathrm{~h}$ of cultivation (Fig. 2A) and exhibited a metabolic and isotopic steady state characterized by constant growth and production performance as well as a constant ${ }^{13} \mathrm{C}$ labeling pattern of amino acids over time (Fig. S2), demonstrating that the chosen steady-state flux approach was justified and applicable (see supplement). A preliminary inspection of the GC-MS and the NMR data revealed that the ${ }^{13} \mathrm{C}$ enrichment of proteinogenic alanine in cells grown on $\left[1-{ }^{13} \mathrm{C}\right]$ mannitol was almost at the level of the tracer (Table 4). Virtually no ${ }^{13} \mathrm{C}$ labeling was removed, as would have been expected for mannitol metabolism via the PP pathway. The ${ }^{13} \mathrm{C}$ label was almost exclusively retained in the carbon atom $\mathrm{C}_{3}$ of alanine, indicating strong use of the EMP pathway. The distribution of intracellular fluxes in the SEA-1 strain revealed that mannitol was oxidized into fructose inside the cell (Fig. 3). On a quantitative basis, the PP pathway flux was only $6 \%$ (Table S2). The fructose thus formed was mainly phosphorylated into fructose 1-phosphate by the PTS $^{\text {Frc }}$ (74\%). The SEA-1 strain did not exhibit fructokinase activity $(<0.1 \mathrm{mU}$ $\left.\mathrm{mg}^{-1}\right)$; hence, the remaining fructose (26\%) was secreted into the medium. Accordingly, fructose entered the central metabolism exclusively at the level of fructose 1,6-bisphosphate. As a consequence of the extremely low PP 


\section{ACCEPTED MANUSCRIPT}

pathway flux, almost all of the carbon was channeled via glycolysis to the pyruvate node, where it was distributed into different pathways. The TCA cycle carried a flux of $69 \%$ and was fully cyclic in the oxidative direction. Smaller fluxes fueled the TCA cycle via anaplerotic carboxylation (21\%) and lysine biosynthesis (11\%). Glycolytic byproducts were formed from the 3phosphoglycerate node (glycine) and the pyruvate node (alanine, acetate, and lactate). In addition, a low flux formed glutamate in the TCA cycle. Comparative studies of the strain on $\left[1-{ }^{13} \mathrm{C}\right]$ fructose and $\left[1-{ }^{13} \mathrm{C}\right]$ glucose indicated greater use of the PP pathway for these two sugars than for mannitol. The PP pathway flux was $18 \%$ and $93 \%$ on fructose and glucose, respectively (Table S2).

\subsection{Heterologous fructokinase enhances lysine production from} mannitol

The low flux through the PP pathway in mannitol-grown C. glutamicum SEA1 provided only very limited amounts of NADPH to drive lysine biosynthesis. In fact, carbon was almost exclusively channeled via fructose 1-phosphate to the lower glycolytic chain. To overcome this bottleneck, the phosphorylation of fructose into fructose 6-phosphate was selected as a strategy to push extra carbon into the PP pathway. The desired modification was realized by the heterologous expression of fructokinase. For this purpose, the $C$. acetobutylicum scrk gene, which encodes fructokinase (EC 2.7.1.4), was inserted into the genome of the SEA-1 strain. The disruption of the lycopene pathway enabled successful integration to be visualized by colony color (positive mutants were red instead of yellowish), but the physiology of the 


\section{ACCEPTED MANUSCRIPT}

cells was otherwise unaffected (Fig. S3). A positive clone from the second recombination, which had PCR fragments of the correct size (2170 bp) and sequence, was designated C. glutamicum SEA-2A. The crude cell extract of the SEA-2A mutant exhibited substantial fructokinase activity $(108 \pm 1 \mathrm{mU}$ $\mathrm{mg}^{-1}$ ) with a high affinity for ATP and fructose (Table 5). The mutant accumulated a higher lysine titer than the parent strain, SEA-1 (Fig. 4A), and had increases in lysine yield and specific productivity (Table 3). The byproduct spectrum revealed slightly increased levels of glutamate and glycine compared to those in the parent strain, but the levels of the other byproducts remained unaffected (Table 2).

\subsection{Combined transcriptional and translational engineering of} fructokinase expression results in higher enzyme amounts and further supports lysine production

The Mak enzyme from E. coli was tested as an alternative fructokinase. Mak was expressed in C. glutamicum as described above and validated by PCR (2120 bp fragment) and sequencing. The generated mutant, SEA-2B, showed a $50 \%$ increase in fructokinase activity compared to that in SEA-2A (Table 5). The affinity of the Mak enzyme for ATP was similar to that of the ScrK variant, but its affinity for fructose was slightly less, albeit still in the submillimolar range. The amplified fructokinase activity was beneficial for production: the lysine yield was increased to $0.20 \mathrm{~mol} \mathrm{~mol}^{-1}$ (Table 3), and the final lysine titer was increased by $25 \%$ to $10.8 \mathrm{mM}$ (Fig. 4B). In addition, the accumulation of fructose was substantially reduced. Slightly increased 


\section{ACCEPTED MANUSCRIPT}

levels of glutamate and glycine compared to those in the parent strain were detected, but the levels of the other byproducts remained unaffected.

\subsection{Influence of fructokinase expression on metabolic fluxes}

C. glutamicum SEA-2B was analyzed at the metabolic flux level to clarify the effects of genomic fructokinase expression. Similar to the basic producer, cells grown on $\left[1-{ }^{13} \mathrm{C}\right]$ mannitol exhibited an isotopic and metabolic steady state (Fig. S4). More fructose was channeled into the central metabolism in the SEA-2B mutant than in the basic producer (Fig. 5A). The efflux of fructose into the medium was reduced to $18 \%$; thus, an increased substrate fraction of $82 \%$ was available for metabolism. The ${ }^{13} \mathrm{C}$ enrichment of alanine was clearly reduced in the presence of fructokinase expression, which sensitively reflected enhanced use of the PP pathway (Table 4). On a quantitative basis, the PP pathway flux was increased to $17 \%$, which reflected the supportive action of fructokinase supplying fructose 6phosphate for entry into the PP pathway. The overall increased substrate influx caused the activation of the EMP pathway, supplied additional carbon at the pyruvate node and stimulated the major routes at this branch point. The fluxes into lysine biosynthesis (13\%) and anaplerosis (24\%) were both enhanced. In addition, a substantial fraction of carbon was channeled into the TCA cycle via pyruvate dehydrogenase (90\%). 


\section{ACCEPTED MANUSCRIPT}

\subsection{Expression of NADPH-dependent glyceraldehyde 3-phosphate}

dehydrogenase is beneficial for lysine production from mannitol

As demonstrated, the addition of an engineered fructokinase gene increased the PP pathway flux in a beneficial manner. However, most of the carbon still bypassed the PP pathway and entered the lower EMP pathway without generating NADPH. The successful supply of more NADPH via the PP pathway seemed somewhat limited. Accordingly, a third round of metabolic engineering was undertaken with the goal of coupling the NADPH supply to the obviously high glycolytic flux in C. glutamicum SEA-2B (Fig. 4, Fig. 5A). For this purpose, NADP-dependent glyceraldehyde 3-phosphate dehydrogenase (GapN) from S. mutans was expressed along with the native NAD-dependent GapA enzyme. SEA-3, the C. glutamicum mutant thus constructed, revealed the desired NADP-dependent activity $(250 \pm 11 \mathrm{mU}$ $\mathrm{mg}^{-1}$ ) in addition to the NAD-specific activity of the native glyceraldehyde 3phosphate dehydrogenase $\left(420 \pm 25 \mathrm{mU} \mathrm{mg}^{-1}\right)$. A control strain carrying the empty plasmid exhibited activity only with NAD as a cofactor $(397 \pm 34 \mathrm{mU}$ $\left.\mathrm{mg}^{-1}\right)$, but not in the presence of $\operatorname{NADP}\left(<0.1 \mathrm{mU} \mathrm{mg}{ }^{-1}\right)$. The novel $C$. glutamicum strain SEA-3 showed substantial improvements in growth and lysine production performance (Fig. 4C). Supported by the modified EMP pathway, SEA-3 consumed all of the mannitol within only $22 \mathrm{~h}$, much faster than the parent strain. Moreover, fructose accumulation was almost completely eliminated. Altogether, this resulted in strongly enhanced lysine formation. The final titer was increased to $14 \mathrm{mM}$ (Fig. 4C), and the yield was increased to $0.24 \mathrm{~mol} \mathrm{~mol}^{-1}$ (Table 3 ). In addition, the specific substrate uptake rate and the specific growth rate were both markedly increased 


\section{ACCEPTED MANUSCRIPT}

(Table 2). In terms of byproducts, slightly increased glycine and glutamate formation was observed.

\subsection{NADPH-coupled glycolysis leads to a massive upregulation of carbon fluxes in mannitol-grown cells}

The engineered C. glutamicum strain SEA-3 showed a global response at the metabolic flux level (Fig. 5B). Again, the flux approach relied on an isotopic and metabolic steady state in the tracer studies that were conducted (Fig. S5). Most strikingly, mannitol uptake flux was upregulated by more than $20 \%$. Fructose excretion was almost abolished, but the sugar was efficiently channeled into the central carbon metabolism, primarily by the fructosespecific PTS and, to a lesser extent, by the heterologous fructokinase. The contribution of the latter was reflected by the PP pathway flux, which was greater than that of the basic strain (Table 4, Table S3). Glycolysis was strongly upregulated, supported by the additional contribution of the NADPHdependent glyceraldehyde 3-phosphate, which carried approximately $23 \%$ of the glycolytic flux at this node. A substantial increase in lysine formation was triggered at the level of pyruvate, which was accompanied by elevated flux into the TCA cycle. The control strain for the gapN mutant, which harbored only the empty plasmid, displayed growth and production characteristics similar to those of SEA-2B, the parent strain without the plasmid (Table 2). This finding confirmed that all flux differences between the producers were attributable to the extra NADPH-dependent glyceraldehyde 3-phosphate dehydrogenase. The performance of $C$. glutamicum grown on mannitol was also studied by in silico pathway simulation, which provided several thousand 
elementary flux modes with different degrees of lysine and biomass formation efficiency (Fig. 6).

\section{Discussion}

\subsection{Bio-based production from mannitol extends the raw material basis for industrial lysine}

Lysine is currently made in the exceptionally large quantity of $2,500,000$ tons per year and is therefore one of the world's leading biotechnological products (Eggeling and Bott, 2015). A highly competitive market forces companies to continuously improve industrial processes. These improvements include the use of attractive, sustainable raw materials beyond the conventional substrates, raw sugar and starch. In the present work, several rounds of metabolic engineering provided a strain that could convert mannitol into remarkable amounts of lysine (Fig. 7). C. glutamicum SEA-3 achieved excellent performance in batch culture (Table 3$)$. Its lysine yield $(0.24 \mathrm{~mol}$

$\left.\mathrm{mol}^{-1}\right)$ and specific lysine production rate $\left(1.1 \mathrm{mmol} \mathrm{g}^{-1} \mathrm{~h}^{-1}\right)$ almost matched the synthesis power of the lysine hyperproducer $C$. glutamicum LYS-12 grown on glucose, which forms lysine at a rate of $1.2 \mathrm{mmol} \mathrm{g}^{-1} \mathrm{~h}^{-1}$ and a yield of $0.25 \mathrm{~mol} \mathrm{~mol}^{-1}$ (Becker et al., 2011). Our novel mutants are directly applicable for the exploitation of the mannitol stream from cascading seaweed fractionation and valorization (van Hal et al., 2014). In the future, mannitol-based lysine production processes could therefore be well integrated with the use of seaweed biomass (Stokstad, 2012). In addition to attractive sustainability, this would facilitate the operation of industrial lysine 


\section{ACCEPTED MANUSCRIPT}

plants in locations such as Asia, Europe, and Africa, which have extensive coastal areas suitable for seaweed farms. In this context, the developed cell factories can be regarded as an innovation that could stimulate the lysine industry.

\subsection{Bio-based production of lysine from mannitol offers a value-added extension for macroalgae biorefineries}

Currently, mannitol and other seaweed ingredients are mainly used for bioethanol production (Enquist-Newman et al., 2014). However, a wide range of microbes have been evaluated for their mannitol utilization and ethanol production capacities in recent years (Kim et al., 2011; Ota et al., 2013; Wang et al., 2013). Although bioethanol production from seaweed biomass is deservedly regarded as a milestone toward third-generation bioproduction (Stokstad, 2012), it will only become competitive in the medium term if considered along with higher-value coproducts (Ullah et al., 2014). In this context, the demonstrated production of lysine from mannitol seems a valuable and promising extension for aquatic biomass refineries. The rich product portfolio available via engineering of $C$. glutamicum highlights the potential future production of more interesting products from mannitol (Becker and Wittmann, 2012; Becker and Wittmann, 2015).

\subsection{The reduced sugar alcohol mannitol strongly impacts metabolic pathway use in C. glutamicum}

As shown in this study, the basic producer SEA-1 secreted fructose. Despite the reutilization of fructose in later cultivation phases, its transient 


\section{ACCEPTED MANUSCRIPT}

accumulation undesirably lengthened the fermentation time. The fructose overflow remained significant even after the expression of fructokinase, in contrast to previously published results with sugar-grown fructokinase mutants (Moon et al., 2005). The remaining overflow indicates a persistent bottleneck in the central metabolism of mannitol-grown $C$. glutamicum. In contrast to sugars, the utilization of mannitol creates NADH during the initial oxidation of the substrate into fructose by mannitol 2-dehydrogenase (Fig. 1). This likely causes the limitation of glyceraldehyde 3-phosphate dehydrogenase, which is known to be inhibited by NADH (Kiefer et al., 2004; Yokota and Lindley, 2005), and explains the observation that the additional expression of GapN, a non-NADH-sensitive glyceraldehyde 3-phosphate dehydrogenase, increased the glycolytic flux (Fig. 5, Fig. 7). It is remarkable that the SEA-3 mutant engineered in this manner metabolized mannitol, which is not a natural substrate of $C$. glutamicum, $40 \%$ more rapidly than $C$. glutamicum wild-type cells metabolized glucose (Becker et al., 2011).

\subsection{Increased lysine production benefits from a supply of NADPH}

Successful lysine production in $C$. glutamicum depends on the supply of NADPH (Bommareddy et al., 2014; Marx et al., 1997; Takeno et al., 2010). The strain genealogy exhibited a stepwise improvement in NADPH supply in response to the engineered genetic changes (Fig. 8A). The basic producer strain SEA-1 showed an apparent limitation of NADPH, but the engineered mutants SEA-2B and SEA-3 exhibited balanced NADPH metabolism and even an apparent NADPH excess, respectively (Fig. 8B). This result nicely reflects the success of the metabolic engineering strategy, which was aimed 
at improving the supply of redox power. The optimized availability of NADPH then efficiently enhanced lysine formation, given the importance of this cofactor. In particular, the contribution of NADPH-dependent glyceraldehyde 3-phosphate appeared beneficial. The PP pathway was shown to provide only a minor share of the redox power, in stark contrast to lysine production in the presence of sugars. The PP pathway is highly active during growth on sugars such as glucose (Marx et al., 1997), sucrose (Wittmann et al., 2004), and xylose (Buschke et al., 2011).

\subsection{Toward optimum lysine production at low PP pathway fluxes}

When cells are grown on sugars, high PP pathway flux is generally regarded as a prerequisite for efficient lysine production (Becker et al., 2007; Becker et al., 2005). This was supported by the computational pathway analysis of mannitol-grown cells (Fig. 6B) and emerged experimentally at the beginning of the strain engineering for mannitol-based production. The initial mutant constructed, C. glutamicum SEA-1, displayed extremely low oxidative PP pathway flux (Fig. 3) and produced only $60 \%$ of the lysine achievable in the almost genetically identical producer LYS-12 on glucose, which predominantly uses the oxidative PP pathway under these conditions (Becker et al., 2011). This finding might intuitively suggest a means to increase the PP pathway flux toward better lysine production from mannitol. However, our findings indicate that this approach could be difficult or even infeasible. First, the SEA-1 strain already possesses a fully engineered PP pathway. It overexpresses the supporting enzyme fructose 1,6-bisphosphatase and all the enzymes in the oxidative and nonoxidative PP pathways (Becker et al., 


\section{ACCEPTED MANUSCRIPT}

2011), but SEA- still has one of the lowest PP pathway fluxes ever observed

in C. glutamicum. Second, the implementation of fructokinase had only limited success (Table 2) and enhanced the oxidative PP pathway flux only slightly (Fig. 5A). Third, the benefit of fructokinase was subsequently lost when other aspects of the metabolism were changed (Fig. 5B). In conclusion, an efficient NADPH supply from mannitol seems to require an alternative strategy independent of the oxidative PP pathway. We successfully used NADPH-dependent glyceraldehyde 3-phosphate dehydrogenase $(\mathrm{GapN})$. The partial coupling of the EMP pathway to the supply of NADPH increased the lysine yield by $60 \%$ to $0.24 \mathrm{~mol} \mathrm{~mol}^{-1}$ and allowed efficient lysine formation with a low contribution from the oxidative PP pathway. GapN was also valuable for increasing lysine production from glucose in $C$. glutamicum because it provided an extra source of NADPH (Takeno et al., 2010). More recently, it was discovered that GapN could even compensate for the absence of the oxidative PP pathway, which is normally the major source of NADPH in C. glutamicum (Takeno et al., 2016). A similar benefit was seen with mannitol as the substrate. The addition of GapN into the metabolic network of $C$. glutamicum substantially enlarges the feasible flux space and enables higher maximum theoretical yields of lysine (up to 0.9 mol mol${ }^{-1}$ ) and higher growth (Fig. 6A). Most importantly, NADPH-coupled glycolysis enables a theoretical yield of almost $0.8 \mathrm{~mol} \mathrm{~mol}^{-1}$ at low PP pathway flux, more than 1.5-fold greater than achievable without such an enzyme (Fig. 6B). 


\section{ACCEPTED MANUSCRIPT}

\subsection{The cellular response to GapN expression is substrate-dependent}

GapN-expressing mutants of $C$. glutamicum have certain growth defects on glucose, which must be counterbalanced by a mutation in the transcription termination factor rho and by time-dependent fine-tuning of the expression levels of GapN and GapA (Takeno et al., 2016). In contrast to glucose, the coexpression of GapN on mannitol does not limit growth but enhances cellular fitness (Table 2). This difference might be due to mannitol being a reduced sugar alcohol, which provides extra NADH during its oxidation to fructose; this might support energy generation, which is strongly perturbed on glucose (Takeno et al., 2016). In addition, glucose-grown GapN strains are reported to have decreased TCA cycle flux (Takeno et al., 2016). This finding contrasts with the highly increased flux through the cycle observed for the mannitol-grown GapN mutant in this study (Fig. 7B). Given the high relevance of the GapN mutation for lysine production, it would be interesting to study the GapN-expressing strains in more detail to better understand the underlying metabolic effects.

\subsection{Metabolic flux distributions provide valuable guidance for strain engineering}

Parallel tracer studies and global parameter estimation from amino acid labeling data have enabled straightforward ${ }^{13} \mathrm{C}$ metabolic flux analyses of $C$. glutamicum on glucose (Wittmann and Heinzle, 2002), fructose (Kiefer et al., 2004), xylose (Buschke et al., 2011), and sucrose (Wittmann et al., 2004) but failed to elucidate the fluxes on mannitol with the same detail. Unlike the sugars examined in those studies, mannitol is a symmetric molecule 


\section{ACCEPTED MANUSCRIPT}

(Cherniak et al., 1998). Although symmetric tracers can be handled by ${ }^{13} \mathrm{C}$ metabolic flux analysis (Schilling et al., 2007), the two commercially available mannitol tracers did not provide sufficient labeling information in the analyzed cell protein to determine all of the fine structures in the network. However, we decided to estimate the major net fluxes through carbon core metabolism, which required only a limited data set: a single labeling measurement in addition to data already collected on substrates and products. Using the obtained net fluxes as guidance for metabolic engineering allowed the lysine yield to be almost doubled (Table 3), convincingly demonstrating the usefulness of this simplified approach. At some point, a more detailed analysis of the metabolic fluxes in mannitol-grown cells could be of interest to better elucidate the underlying physiology, but this would require substantial additional effort. Approaches to solve this problem might include searching for additional labeling information from other cellular metabolites, providing other mannitol tracers, or applying isotopically nonstationary approaches (Nöh et al., 2007).

\section{Conclusions}

In this study, we demonstrated efficient lysine production from mannitol using a metabolically engineered $C$. glutamicum cell factory. The SEA-3 strain comprises a set of 15 genetic changes that streamline it for fast substrate uptake and a high level of product formation. Our findings open the door for the use of seaweed biomass for the production of lysine and other products accessible with C. glutamicum in the future. In 2012, global seaweed 


\section{ACCEPTED MANUSCRIPT}

production was approximately 3 million tons and is projected to reach 500 million tons of dried seaweed by 2050 .

\section{Acknowledgments}

The authors acknowledge the valuable support of Michel Fritz with the analytics.

\section{References}

Becker, J., Buschke, N., Bücker, R., Wittmann, C., 2010. Systems level engineering of Corynebacterium glutamicum - reprogramming translational efficiency for superior production. Eng. Lif. Sci. 10, 430438.

Becker, J., Gießelmann, G., Hoffmann, S. L., Wittmann, C., 2016. Corynebacterium glutamicum for sustainable bio-production: From metabolic physiology to systems metabolic engineering. In: Zhao, H., Zeng, A. P., Eds.), Synthetic Biology - Metabolic Engineering. Springer, Heidelberg.

Becker, J., Klopprogge, C., Herold, A., Zelder, O., Bolten, C. J., Wittmann, C., 2007. Metabolic flux engineering of L-lysine production in Corynebacterium glutamicum--over expression and modification of G6P dehydrogenase. J. Biotechnol. 132, 99-109.

Becker, J., Klopprogge, C., Zelder, O., Heinzle, E., Wittmann, C., 2005. Amplified expression of fructose 1,6-bisphosphatase in Corynebacterium glutamicum increases in vivo flux through the pentose phosphate pathway and lysine production on different carbon sources. Appl. Environ. Microbiol. 71, 8587-96.

Becker, J., Wittmann, C., 2012. Bio-based production of chemicals, materials and fuels -Corynebacterium glutamicum as versatile cell factory. Curr. Opin. Biotechnol. 23, 631-40. 


\section{ACCEPTED MANUSCRIPT}

Becker, J., Wittmann, C., 2015. Advanced biotechnology: Metabolically engineered cells for the bio-based production of chemicals and fuels, materials, and health-care products. Angew. Chem. Int. Ed. Engl. 54, 3328-3350.

Becker, J., Zelder, O., Haefner, S., Schröder, H., Wittmann, C., 2011. From zero to hero--design-based systems metabolic engineering of Corynebacterium glutamicum for L-lysine production. Metab. Eng. 13, 159-68.

Bommareddy, R. R., Chen, Z., Rappert, S., Zeng, A. P., 2014. A de novo NADPH generation pathway for improving lysine production of Corynebacterium glutamicum by rational design of the coenzyme specificity of glyceraldehyde 3-phosphate dehydrogenase. Metab. Eng. 25, 30-7.

Buschke, N., Becker, J., Schäfer, R., Kiefer, P., Biedendieck, R., Wittmann, C., 2013a. Systems metabolic engineering of xylose-utilizing Corynebacterium glutamicum for production of 1,5-diaminopentane. Biotechnol. J. 8, 557-70.

Buschke, N., Schäfer, R., Becker, J., Wittmann, C., 2013b. Metabolic engineering of industrial platform microorganisms for biorefinery applications--optimization of substrate spectrum and process robustness by rational and evolutive strategies. Bioresour. Technol. $135,544-54$.

Buschke, N., Schröder, H., Wittmann, C., 2011. Metabolic engineering of Corynebacterium glutamicum for production of 1,5-diaminopentane from hemicellulose. Biotechnol. J. 6, 306-17.

Cherniak, R., O'Neill, E. B., Sheng, S., 1998. Assimilation of xylose, mannose, and mannitol for synthesis of glucuronoxylomannan of Cryptococcus neoformans determined by ${ }^{13} \mathrm{C}$ nuclear magnetic resonance spectroscopy. Infect. Immun. 66, 2996-8.

Christensen, B., Thykaer, J., Nielsen, J., 2000. Metabolic characterization of high- and low-yielding strains of Penicillium chrysogenum. Appl. Microbiol. Biotechnol. 54, 212-7. 


\section{ACCEPTED MANUSCRIPT}

Crow, V. L., Wittenberger, C. L., 1979. Separation and properties of NAD+and NADP+-dependent glyceraldehyde-3-phosphate dehydrogenases from Streptococcus mutans. J. Biol. Chem. 254, 1134-42.

Eggeling, L., Bott, M., 2015. A giant market and a powerful metabolism: Llysine provided by Corynebacterium glutamicum. Appl. Microbiol. Biotechnol. 99, 3387-94.

Enquist-Newman, M., Faust, A. M. E., Bravo, D. D., Santos, C. N. S., Raisner, R. M., Hanel, A., Sarvabhowman, P., Le, C., Regitsky, D. D., Cooper, S. R., 2014. Efficient ethanol production from brown macroalgae sugars by a synthetic yeast platform. Nature. 505, 239243.

Gibson, D. G., Young, L., Chuang, R. Y., Venter, J. C., Hutchison, C. A., 3rd, Smith, H. O., 2009. Enzymatic assembly of DNA molecules up to several hundred kilobases. Nat. Methods. 6, 343-5.

Goh, C. S., Lee, K. T., 2010. A visionary and conceptual macroalgae-based third-generation bioethanol (TGB) biorefinery in Sabah, Malaysia as an underlay for renewable and sustainable development. Renewable and Sustainable Energy Reviews. 14, 842-848.

Iwamoto, K., Shiraiwa, Y., 2005. Salt-regulated mannitol metabolism in algae. Marine Biotechnology. 7, 407-415.

Kawaguchi, H., Vertes, A. A., Okino, S., Inui, M., Yukawa, H., 2006. Engineering of a xylose metabolic pathway in Corynebacterium glutamicum. Appl. Environ. Microbiol. 72, 3418-28.

Kiefer, P., Heinzle, E., Zelder, O., Wittmann, C., 2004. Comparative metabolic flux analysis of lysine-producing Corynebacterium glutamicum cultured on glucose or fructose. Appl. Environ. Microbiol. 70, 229-39.

Kim, I. K., Jeong, W. K., Lim, S. H., Hwang, I. K., Kim, Y. H., 2011. The small ribosomal protein S12P gene rpsL as an efficient positive selection marker in allelic exchange mutation systems for Corynebacterium glutamicum. J. Microbiol. Methods. 84, 128-30.

Koffas, M., Stephanopoulos, G., 2005. Strain improvement by metabolic engineering: lysine production as a case study for systems biology. Curr. Opin. Biotechnol. 16, 361-6. 


\section{ACCEPTED MANUSCRIPT}

Kotrba, P., Inui, M., Yukawa, H., 2003. A single V317A or V317M substitution in Enzyme II of a newly identified beta-glucoside phosphotransferase and utilization system of Corynebacterium glutamicum $\mathrm{R}$ extends its specificity towards cellobiose. Microbiology. 149, 1569-80.

Krömer, J. O., Fritz, M., Heinzle, E., Wittmann, C., 2005. In vivo quantification of intracellular amino acids and intermediates of the methionine pathway in Corynebacterium glutamicum. Anal. Biochem. 340, 171-3.

Marx, A., Striegel, K., de Graaf, A. A., Sahm, H., Eggeling, L., 1997. Response of the central metabolism of Corynebacterium glutamicum to different flux burdens. Biotechnol. Bioeng. 56, 168-80.

Melzer, G., Esfandabadi, M. E., Franco-Lara, E., Wittmann, C., 2009. Flux Design: In silico design of cell factories based on correlation of pathway fluxes to desired properties. BMC Syst. Biol. 3, 120.

Moon, M.-W., Kim, H.-J., Oh, T.-K., Shin, C.-S., Lee, J.-S., Kim, S.-J., Lee, J.-K., 2005. Analyses of enzyme II gene mutants for sugar transport and heterologous expression of fructokinase gene in Corynebacterium glutamicum ATCC 13032. FEMS Microbiol. Lett. 244, 259-266.

Moon, M. W., Park, S. Y., Choi, S. K., Lee, J. K., 2007. The phosphotransferase system of Corynebacterium glutamicum: features of sugar transport and carbon regulation. J. Mol. Microbiol. Biotechnol. $12,43-50$.

Naik, S. N., Goud, V. V., Rout, P. K., Dalai, A. K., 2010. Production of first and second generation biofuels: A comprehensive review. Renewable and Sustainable Energy Reviews. 14, 578-597.

Nöh, K., Gronke, K., Luo, B., Takors, R., Oldiges, M., Wiechert, W., 2007. Metabolic flux analysis at ultra short time scale: isotopically nonstationary ${ }^{13} \mathrm{C}$ labeling experiments. J. Biotechnol. 129, 249-67.

Ota, A., Kawai, S., Oda, H., Iohara, K., Murata, K., 2013. Production of ethanol from mannitol by the yeast strain Saccharomyces paradoxus NBRC 0259. J. Biosci. Bioeng. 116, 327-32.

Peng, X., Okai, N., Vertes, A. A., Inatomi, K., Inui, M., Yukawa, H., 2011. Characterization of the mannitol catabolic operon of Corynebacterium glutamicum. Appl. Microbiol. Biotechnol. 91, 1375-87. 


\section{ACCEPTED MANUSCRIPT}

Quek, L. E., Wittmann, C., Nielsen, L. K., Krömer, J. O., 2009. OpenFLUX: efficient modelling software for ${ }^{13} \mathrm{C}$-based metabolic flux analysis. Microb. Cell Fact. 8, 25.

Rasmus, B., Valderrama, D., Radulovich, R., Diana, J., Capron, M., Mckinnie, C., Amir Cedric, M., Hopkins, K., Yarish, C., Goudey, C., Forster, J., Seaweed aquaculture for food security, income generation and environmental health in Tropical Developing Countries. World Bank Group, Washington, D.C., 2016.

Rohles, C. M., Giesselmann, G., Kohlstedt, M., Wittmann, C., Becker, J., 2016. Systems metabolic engineering of Corynebacterium glutamicum for the production of the carbon-5 platform chemicals 5-aminovalerate and glutarate. Microb. Cell Fact. 15, 154.

Ryu, S., Karim, M. N., 2011. A whole cell biocatalyst for cellulosic ethanol production from dilute acid-pretreated corn stover hydrolyzates. Appl. Microbiol. Biotechnol. 91, 529-542.

Sasaki, M., Jojima, T., Inui, M., Yukawa, H., 2008. Simultaneous utilization of D-cellobiose, D-glucose, and D-xylose by recombinant Corynebacterium glutamicum under oxygen-deprived conditions. Appl. Microbiol. Biotechnol. 81, 691-9.

Schilling, O., Frick, O., Herzberg, C., Ehrenreich, A., Heinzle, E., Wittmann, C., Stulke, J., 2007. Transcriptional and metabolic responses of Bacillus subtilis to the availability of organic acids: transcription regulation is important but not sufficient to account for metabolic adaptation. Appl. Environ. Microbiol. 73, 499-507.

Schneider, J., Niermann, K., Wendisch, V. F., 2011. Production of the amino acids I-glutamate, I-lysine, I-ornithine and I-arginine from arabinose by recombinant Corynebacterium glutamicum. J. Biotechnol. 154, 191-8.

Stokstad, E., 2012. Biofuels. Engineered superbugs boost hopes of turning seaweed into fuel. Science. 335, 273.

Takeno, S., Hori, K., Ohtani, S., Mimura, A., Mitsuhashi, S., Ikeda, M., 2016. I-Lysine production independent of the oxidative pentose phosphate pathway by Corynebacterium glutamicum with the Streptococcus mutans gapN gene. Metab. Eng. 37, 1-10. 


\section{ACCEPTED MANUSCRIPT}

Takeno, S., Murata, R., Kobayashi, R., Mitsuhashi, S., Ikeda, M., 2010. Engineering of Corynebacterium glutamicum with an NADPHgenerating glycolytic pathway for L-lysine production. Appl. Environ. Microbiol. 76, 7154-60.

Tan, K. T., Lee, K. T., Mohamed, A. R., 2008. Role of energy policy in renewable energy accomplishment: The case of second-generation bioethanol. Energy Policy. 36, 3360-3365.

Tiwari, B. K., Troy, D. J., 2015. Seaweed sustainability: Food and non-food applications. Elsevier Inc., Heidelberg.

Ullah, K., Ahmad, M., Sofia, Sharma, V. K., Lu, P., Harvey, A., Zafar, M., Sultana, S., Anyanwu, C. N., 2014. Algal biomass as a global source of transport fuels: Overview and development perspectives. Progress in Natural Science: Materials International. 24, 329-339.

van Hal, J. W., Huijgen, W. J. J., López-Contreras, A. M., 2014. Opportunities and challenges for seaweed in the biobased economy. Trends Biotechnol. 32, 231-233.

van Winden, W. A., Wittmann, C., Heinzle, E., Heijnen, J. J., 2002. Correcting mass isotopomer distributions for naturally occurring isotopes. Biotechnol. Bioeng. 80, 477-9.

Wang, J., Kim, Y. M., Rhee, H. S., Lee, M. W., Park, J. M., 2013. Bioethanol production from mannitol by a newly isolated bacterium, Enterobacter sp. JMP3. Bioresour. Technol. 135, 199-206.

Wittmann, C., 2007. Fluxome analysis using GC-MS. Microb. Cell Fact. 6, 6.

Wittmann, C., Becker, J., 2007. The L-lysine story. From metabolic pathways to industrial production. In: Wendisch, V. F., (Ed.), Amino Acid Biosynthesis - Pathways, Regulation and Metabolic Engineering. vol. 5. Springer, Berlin Heidelberg, pp. 40 - 68.

Wittmann, C., De Graaf, A. A., 2005. Metabolic flux analysis in Corynebacterium glutamicum. In: Eggeling, L., Bott, M., Eds.), Handbook of Corynebacterium glutamicum. CRC Press, Boca Raton, pp. 277-304.

Wittmann, C., Hans, M., Heinzle, E., 2002. In vivo analysis of intracellular amino acid labelings by GC/MS. Anal. Biochem. 307, 379-82. 


\section{ACCEPTED MANUSCRIPT}

Wittmann, C., Heinzle, E., 2002. Genealogy profiling through strain improvement by using metabolic network analysis: metabolic flux genealogy of several generations of lysine-producing Corynebacteria. Appl. Environ. Microbiol. 68, 5843-59.

Wittmann, C., Kiefer, P., Zelder, O., 2004. Metabolic fluxes in Corynebacterium glutamicum during lysine production with sucrose as carbon source. Appl. Environ. Microbiol. 70, 7277-87.

Wittmann, C., Kim, H. M., John, G., Heinzle, E., 2003. Characterization and application of an optical sensor for quantification of dissolved $\mathrm{O}_{2}$ in shake-flasks. Biotechnol. Lett. 25, 377-80.

Yokota, A., Lindley, N. D., 2005. Central metabolism: sugar uptake and conversion. In: Eggeling, L., Bott, M., Eds.), Handbook of Corynebacterium glutamicum. CRC Press, Boca Raton, pp. 215-240.

Fig 1: Mannitol operon (A) and mannitol catabolism (B) in Corynebacterium glutamicum. The proteins were encoded by the corresponding genes: $m t / R$, mannitol repressor; $m t / T$, mannitol transporter; $m t I D$, mannitol 2-dehydrogenase; pts $F$, fructose-specific phosphotransferase system; pfkB, fructose 1-phosphate kinase.

Fig 2: Growth and production characteristics of Corynebacterium glutamicum SEA-1 using mannitol as the sole carbon source. The two phases of fructose accumulation (phase I) and reconsumption (phase II) are highlighted in the culture profile $(A)$. The stoichiometry of substrate consumption and product formation relates to the two phases, and the formation of lysine refers to the uptake of mannitol (phase I) and the uptake of mannitol plus fructose (phase II) (B). The formation of lysine was constant over time in each phase $(\mathrm{C})$. The data represent the mean values and corresponding standard deviations from three biological replicates. 


\section{ACCEPTED MANUSCRIPT}

Fig 3: In vivo carbon flux distribution in the central metabolism of lysine-producing Corynebacterium glutamicum SEA-1 during growth on mannitol. All fluxes are expressed as the molar percentage of the corresponding mean specific mannitol uptake rate $\left(q_{s}=6.1 \mathrm{mmol} \mathrm{g}^{-1} \mathrm{~h}^{-1}\right)$, which was set to $100 \%$. The thickness of the reaction arrows represents the flux amount.

Fig 4: Growth and production characteristics of Corynebacterium glutamicum SEA-2A (A), SEA-2B (B), and SEA-3 (C), engineered for lysine production from mannitol. The two phases of fructose accumulation (phase I) and reconsumption (phase II) are highlighted in the culture profiles. The data represent the mean values and corresponding standard deviations from three biological replicates.

Fig 5: In vivo carbon flux distributions in the central metabolism of lysine-producing Corynebacterium glutamicum strains SEA-2B (A) and SEA-3 (B) during growth on mannitol. All fluxes are expressed as the molar percentage of the corresponding mean specific mannitol uptake rate $\left(q_{s}=6.3 \mathrm{mmol} \mathrm{g}^{-1} \mathrm{~h}^{-1}\right.$ for SEA-2B, and $\mathrm{q}_{\mathrm{s}}=7.5 \mathrm{mmol} \mathrm{g}^{-1} \mathrm{~h}^{-1}$ for SEA-3) shown in Table 2, which was set to $100 \%$. The thickness of the reaction arrows represents the flux amount. The color code highlights the flux differences compared to the basic strain SEA-1.

Fig 6: Evaluation of the lysine production performance of Corynebacterium glutamicum by computational elementary flux mode analysis. The in silico flux space for lysine production from mannitol was calculated for the basic strain SEA-1 (network see Table S11) and the best producer SEA-3, which additionally expressed fructokinase and NADPH- 


\section{ACCEPTED MANUSCRIPT}

dependent glyceraldehyde 3-phosphate dehydrogenase (network see Table S13). The yields of lysine and biomass, corresponding to individual elementary modes of SEA-1 (gray squares) and SEA-3 (gray squares plus blue squares), are located within a triangular zone that spans the theoretical production capacity for each mutant $(A)$. In addition, the created strains are displayed as red triangles, reflecting their performance: SEA-1 (1), SEA-2A (2), SEA-2B, and SEA-3 (3). All strains were investigated under shake flask cultivation in minimal mannitol medium. The genetic changes in each strain are summarized in Table 1. The impact of the PP pathway on lysine production was extracted from the calculated elementary flux modes for each strain (B). The feasible flux space of SEA-3 (gray + blue area) was significantly larger than that of the basic strain SEA-1 (gray area). The corresponding individual elementary modes are given by the gray squares (SEA-1) and by the gray + blue squares (SEA-3). In addition, strains SEA-1, SEA-2A, SEA-2B, and SEA-3, which produced lysine from mannitol, are integrated into the flux space according to their intracellular fluxes (orange triangles). The corresponding flux data from the previously engineered $C$. glutamicum strain genealogy LYS-1 to LYS-12, which produce lysine from glucose (green triangles) (Becker et al., 2011), and from the GapNexpressing C. glutamicum mutant RE2/pCAK311, which also produces lysine from glucose (yellow triangle) (Takeno et al., 2016), are also displayed. All strains were investigated under shake flask cultivation.

Fig 7: Systems metabolic engineering of Corynebacterium glutamicum for lysine production from mannitol. The data comprise the absolute carbon fluxes in the central metabolism of the cell factories SEA-2B $(A)$ and 


\section{ACCEPTED MANUSCRIPT}

SEA-3 (B) and the genomic traits engineered into the strains. The absolute fluxes were derived from the specific mannitol uptake rate (Table 2) and the relative flux distributions (Fig. 5A, B). The thickness of the reaction arrows represents the flux amount. The color code reflects the flux differences from the basic strain SEA-1. The genomic traits include feedback decoupling and overexpression of the transketolase operon $\left(P_{\text {sod }} t k t\right)$, overexpression of fructose 1,6-bisphosphatase $\left(P_{\text {tuf }} \quad f b p\right)$, feedback decoupling and overexpression of pyruvate carboxylase $\left(P_{\text {sod }}\right.$ pycA $\left.A^{P 458 S}\right)$, deletion of phosphoenolpyruvate carboxykinase ( $\Delta p c k)$, attenuation of isocitrate dehydrogenase (icd ${ }^{\text {att }}$ ), feedback decoupling and overexpression of aspartokinase $\left(P_{\text {sod }}\right.$ lys $\left.C^{T 3111}\right)$, attenuation of homoserine dehydrogenase $\left(\right.$ hom $\left.^{V 59 A}\right)$, overexpression of 4-hydroxy-tetrahydrodipicolinate reductase $\left(P_{\text {sod }}\right.$ $d a p B)$, overexpression of diaminopimelate dehydrogenase (2x $d d h)$, overexpression of lysine decarboxylase (2x/ysA), deletion of the mannitol repressor $(\Delta m t / R)$, expression of fructokinase from $E$. coli $\left(P_{\text {sod }}\right.$ mak), and expression of NADPH-dependent glyceraldehyde 3-phosphate dehydrogenase from S. mutans (pClik 5a gapN).

\section{Fig 8: NADPH metabolism in mannitol-grown Corynebacterium}

glutamicum. The data comprise the relative fluxes of the NADPH supply (left column, blue) and demand (right column, orange) in the engineered lysineproducers SEA-1, SEA-2B, and SEA-3 (A) and the apparent NADPH excess (B), calculated from the difference between supply and demand. The NADPH supply was inferred from the relative fluxes through the PP pathway enzymes glucose 6-phosphate dehydrogenase and 6-phosphogluconate dehydrogenase (dark blue), isocitrate dehydrogenase (medium blue), and NADPH- 


\section{ACCEPTED MANUSCRIPT}

dependent glyceraldehyde 3-phosphate dehydrogenase (light blue, SEA-3 only) (Fig. 3, Fig. 5A, B). The NADPH requirement for growth (light orange) was estimated from the previously determined demand of $16.4 \mathrm{mmol} \mathrm{NADPH}$ (g biomass) ${ }^{-1}$ (Wittmann and De Graaf, 2005) and the biomass yields for the different strains measured in the present work (Table 2). The amount of NADPH needed for lysine synthesis (dark orange) was determined from the relative lysine flux (Fig. 4, Fig. 6A, B) and the stoichiometric NADPH demand of $4 \mathrm{~mol}$ (mol lysine) $)^{-1}$.

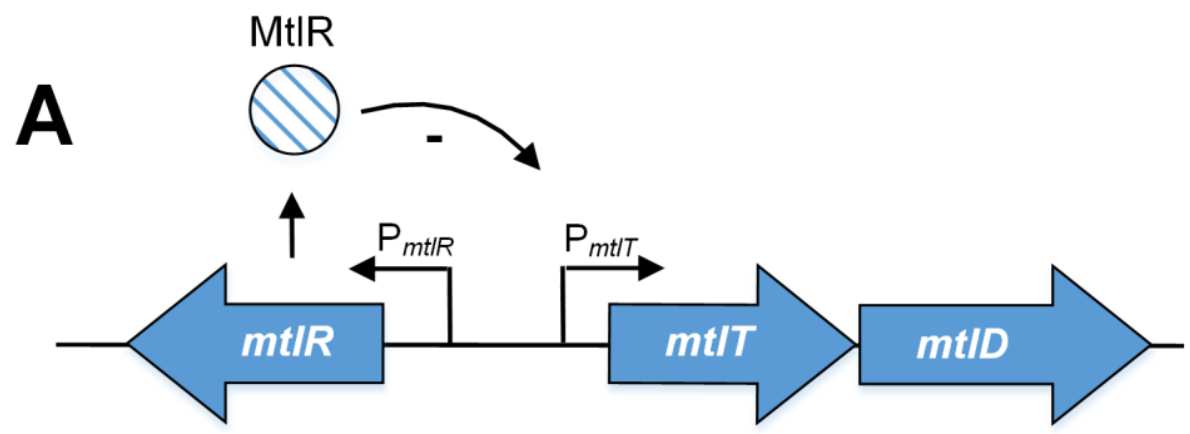

B
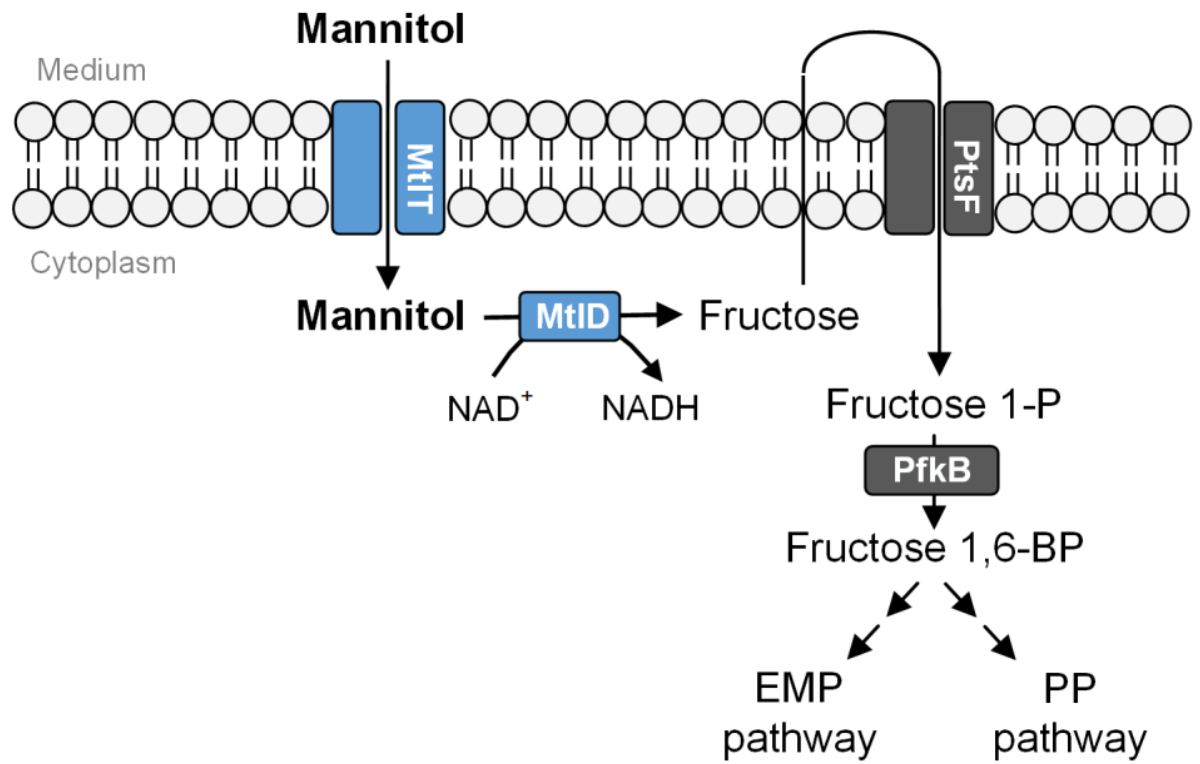

Fig. 1 
Auf yield

bezogen:

zusätzliche

Yachse für frc

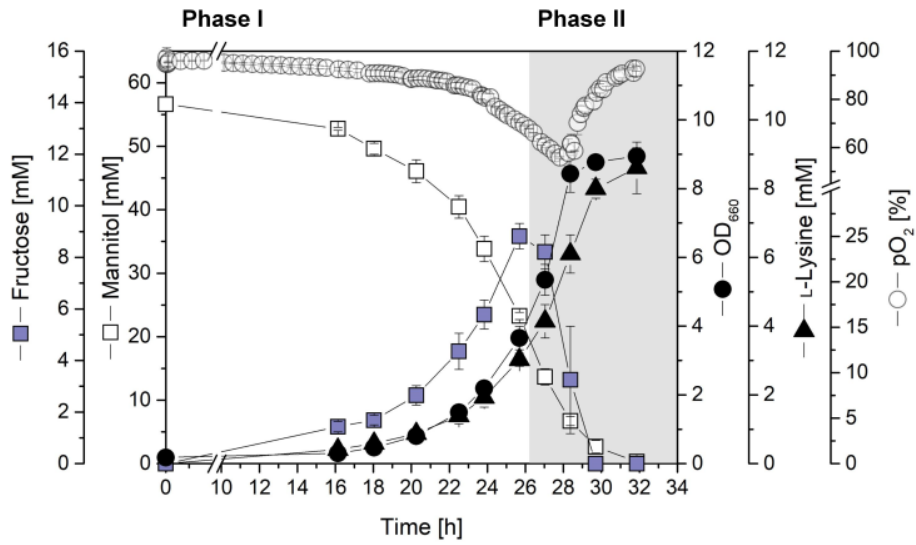

Fig. 2 


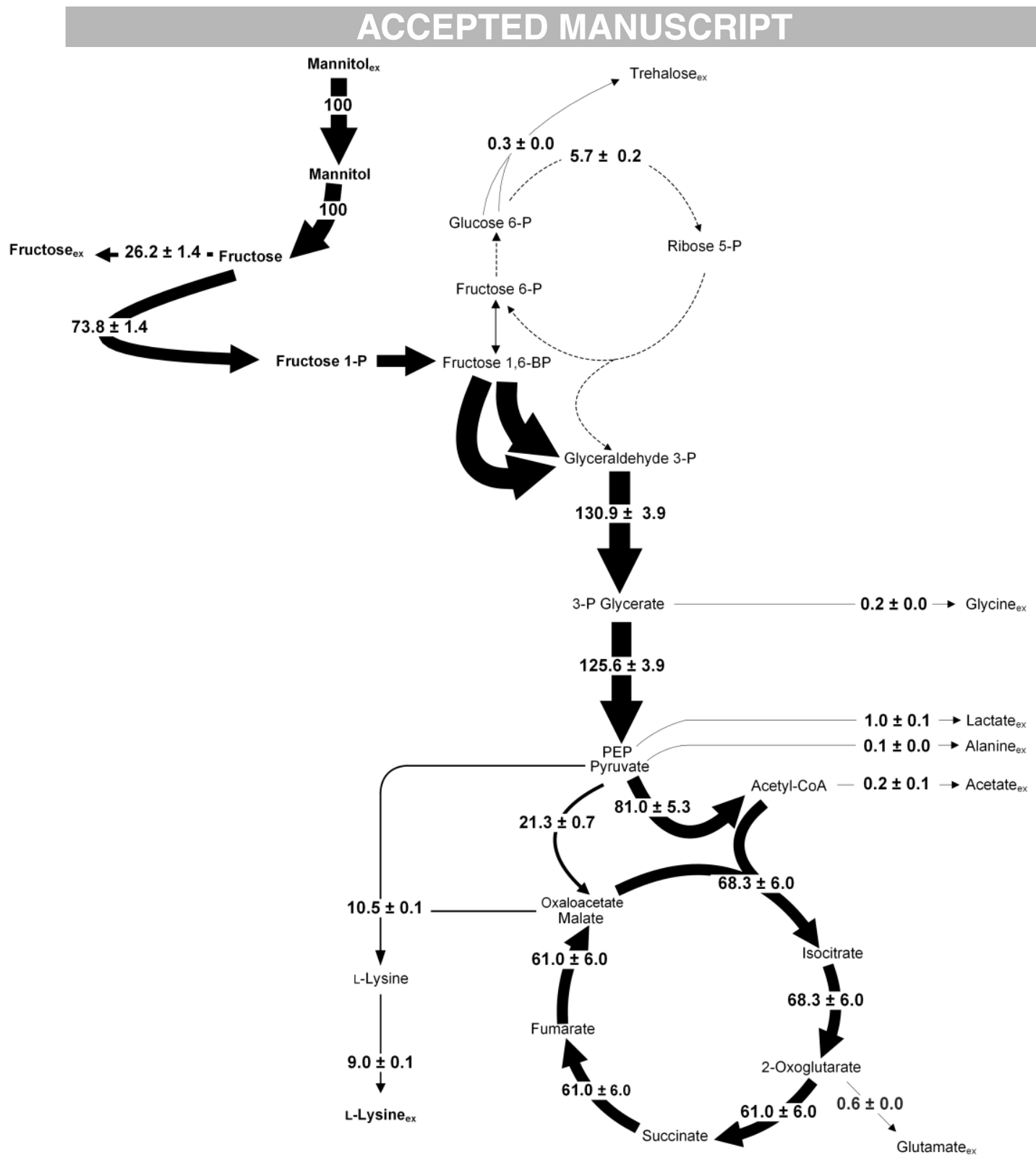

Fig. 3 


\section{ACCEPTED MANUSCRIPT}
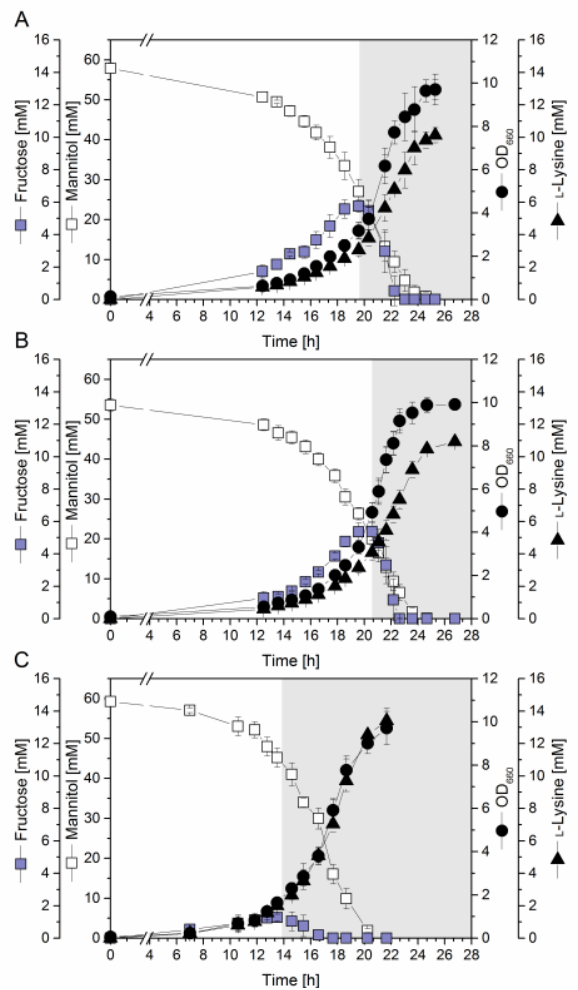

Fig. 4

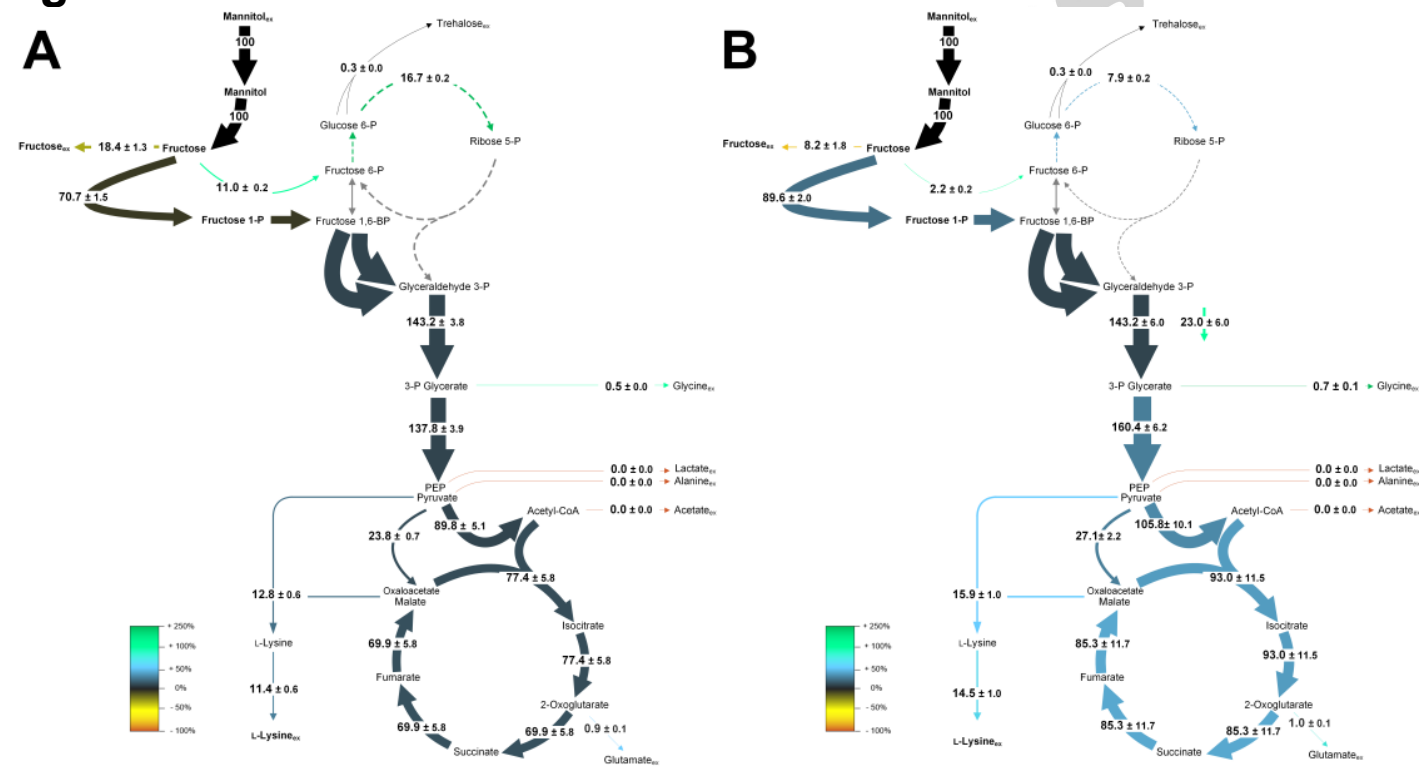

Fig. 5 


\section{ACCEPTED MANUSCRIPT}

A

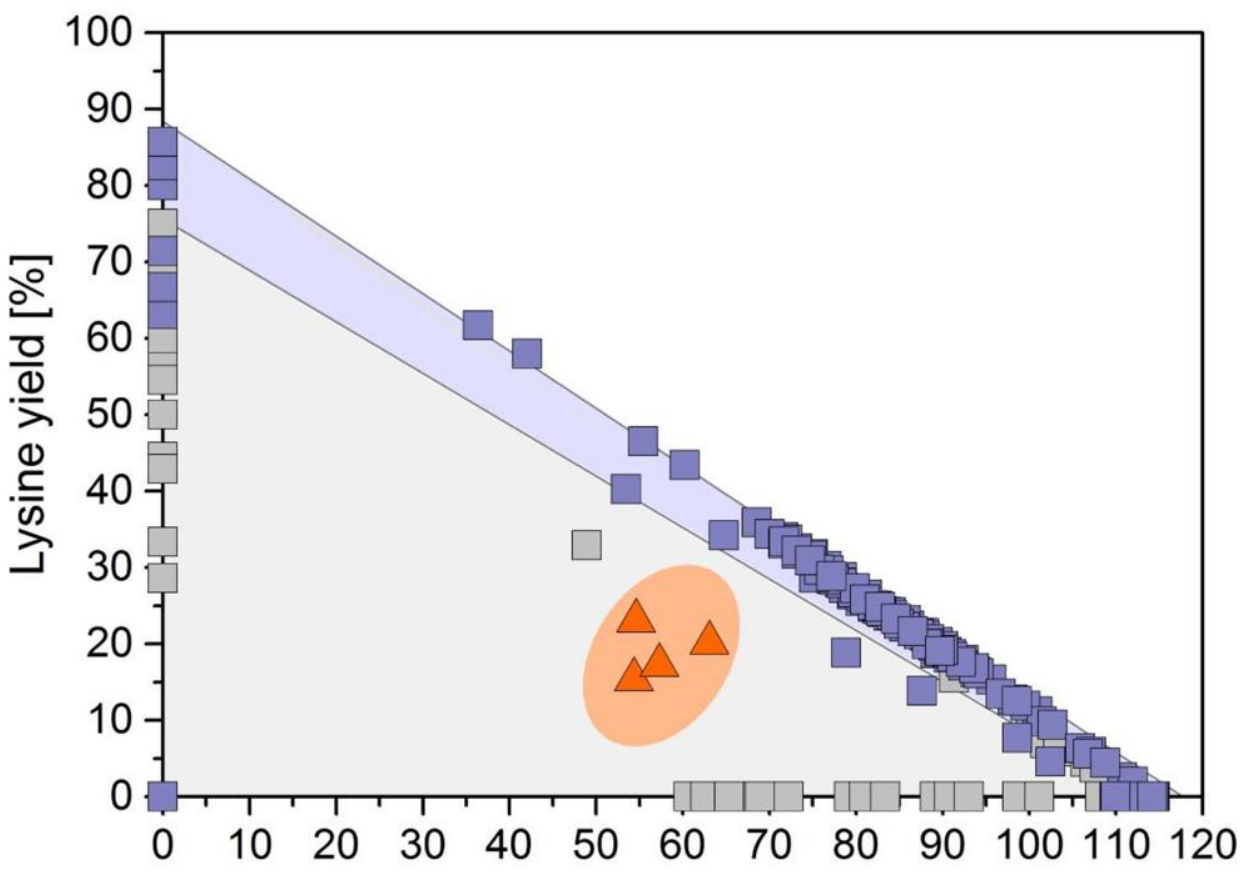

B

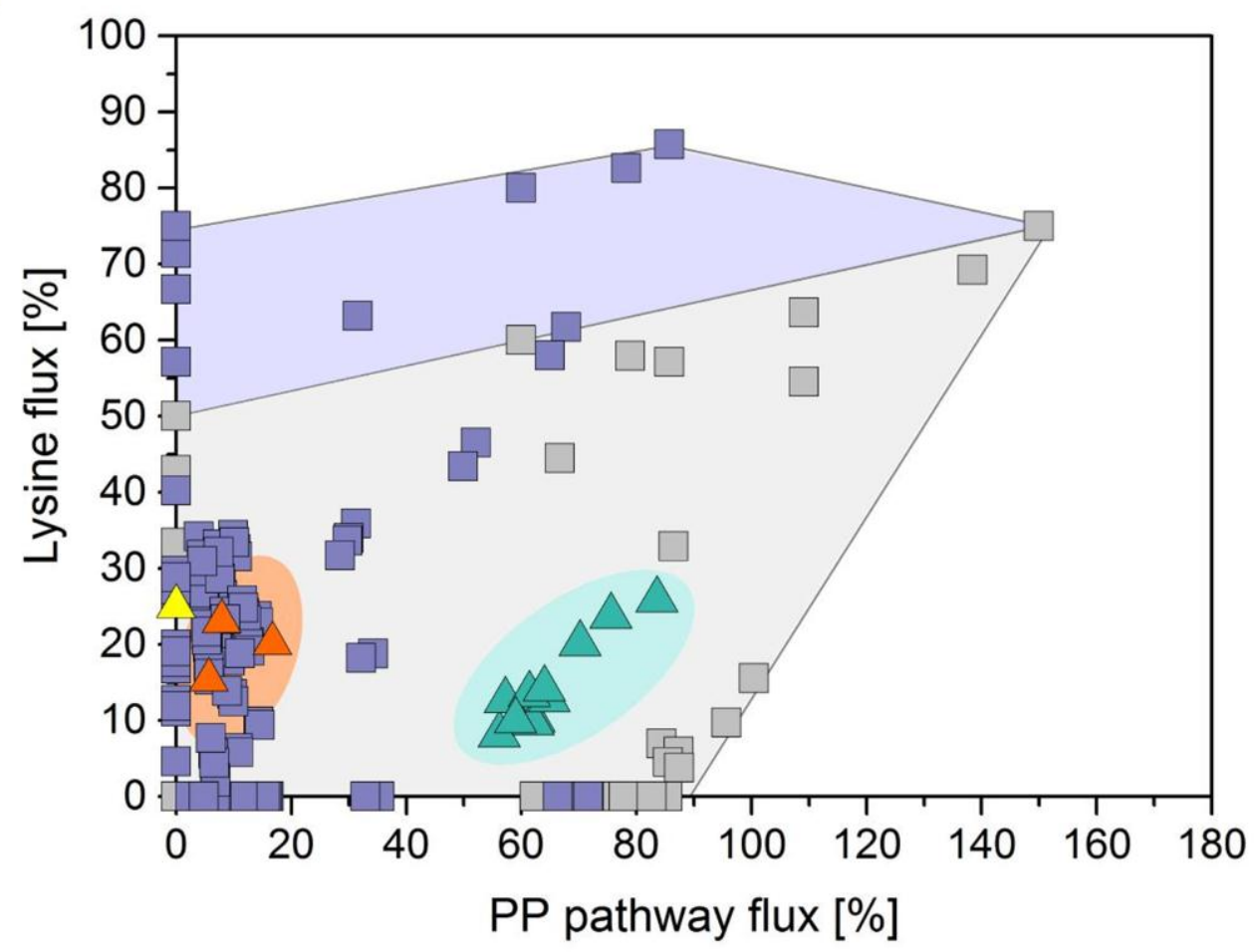

Fig. 6 


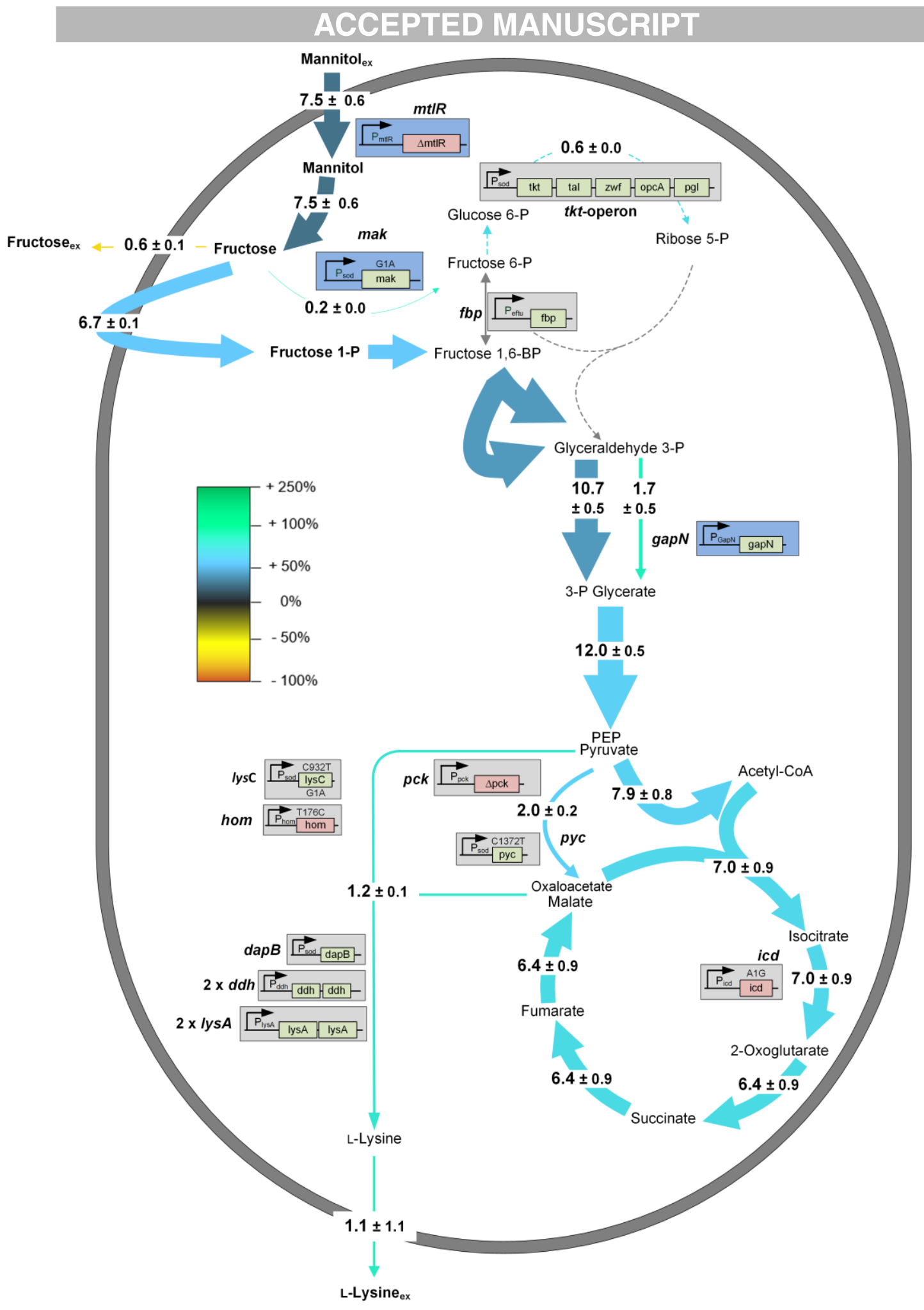

Fig. 7 


\section{ACCEPTED MANUSCRIPT}

A

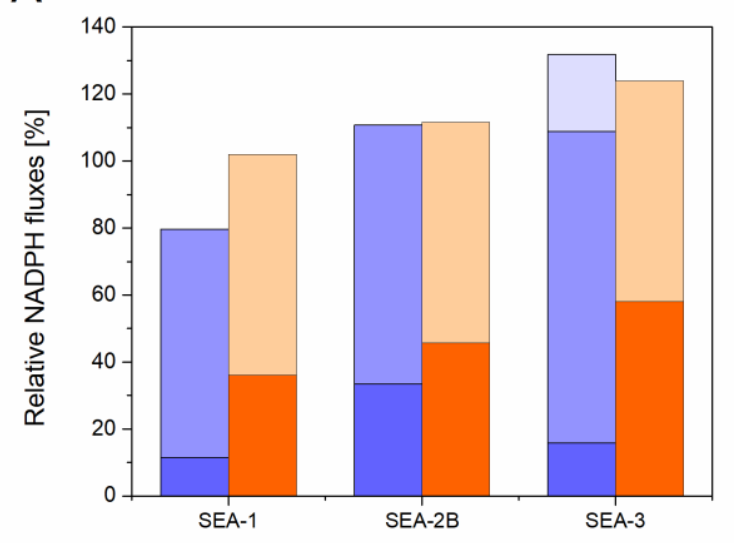

B

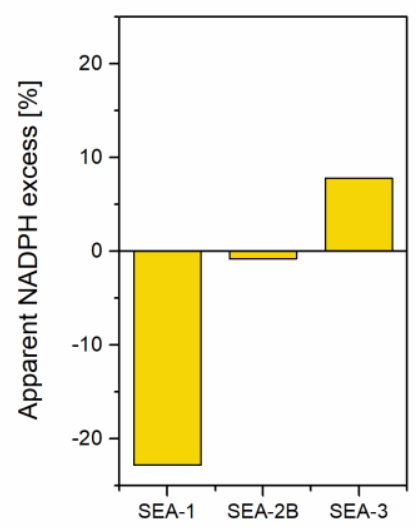

Fig. 8 
Table 1: Strains and plasmids used in this study.

\section{Description}

Reference

\section{Strains}

E. coli DH5a

E. coli NM522

C. glutamicum LYS-12

Lysine-producing strain with 12 genome-based modifications

C. glutamicum SEA-1

LYS-12 + deletion of the $m t / R$ gene (NCgl0110)

Invitrogen

Heat shock-competent cells for amplification of the transformation vector

Invitrogen

Heat shock-competent cells for amplification and methylation of the transformation

vector

(Becker et al., 2011)

C. glutamicum SEA-2A

SEA-1 + genome-based integration of the scrK gene (ID1116607) from $C$. acetobutylicum ATCC 824, encoding fructokinase, into the crtEb gene locus (NCgl0594)

C. glutamicum SEA-2B SEA-1 + genome-based integration of the mak gene (EG11288) from E. coli K12MG1655, encoding fructokinase, into the crtEb gene locus (NCgl0594) +

This work replacement of the translational start codon GTG by ATC in the mak gene

C. glutamicum SEA-3 SEA-2B + plasmid-based expression of the gapN gene (NP_7211104) from Streptococcus mutans UA159, encoding NADPH-dependent glyceraldehyde 3This work phosphate dehydrogenase

C. glutamicum SEA-3 SEA-2B containing the empty episomal plasmid pClik 5a Control

\section{Plasmids}

pTC

Expression vector for DNA-methyltransferase of C. glutamicum, containing an origin of replication (ORI) for E. coli and tetracycline resistance

pClik int sacB Integrative transformation vector for genome-based modifications, comprising an MCS for C. glutamicum, an ORI for E. coli, and $\operatorname{Kan}^{\mathrm{R}}$ and $\operatorname{sacB}$ as selection markers

pClik int $\operatorname{sac} B \Delta m t / R$ pClik int sacB $P_{\text {sodmak }}$ pClik int sacB $P_{\text {sodSCrK }}$ pClik 5a MCS

pClik 5a MCS gapN

\section{Transformation vector for deletion of the mannitol repressor MtIR}

Transformation vector for integration of the mak gene into the crtEb locus

Transformation vector for integration of the scrK gene into the crtEb locus

Episomal replicating vector containing origins of replication (ORIs) for $C$. glutamicum and E. coli and $\mathrm{Kan}^{\mathrm{R}}$ as a selection marker

Episomal replicating vector with gapN (SMU_676) under control of the native promotor
This work

This work

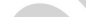

(Becker et al., 2011)

(Becker et al., 2005)

This work

This work

This work

(Buschke et al., 2011)

This work 


\section{ACCEPTED MANUSCRIPT}

Table 2: Growth kinetics and stoichiometry of metabolically engineered strains of Corynebacterium glutamicum. The data reflect the metabolically and isotopically balanced phase of the cultures (Fig. S2, Fig. S4, Fig. S5), which was characterized by fructose accumulation and is highlighted in white in the growth profiles (Fig. 2, Fig. 4). Shown are the specific rates of growth $(\mu)$, mannitol uptake $\left(q_{s}\right)$, and lysine formation ( $\left.q_{\text {Lys }}\right)$ and the yields of lysine $\left(\mathrm{Y}_{\mathrm{Lys} / \mathrm{S}}\right)$, biomass $\left(\mathrm{Y}_{\mathrm{X} / \mathrm{S}}\right)$ and the secreted byproducts fructose (FrC), trehalose (Tre), glycine (Gly), alanine (Ala), acetate (Ace), lactate (Lac), and glutamate (Glu). The strain genealogy comprised the strains SEA-1, SEA-2A, SEA-2B, and SEA-3, all of which were based on the lysine producer $C$. glutamicum LYS-12 (Becker et al., 2011). In addition, the control strain for SEA-3 (SEA-3 control) expressed the empty vector. The data represent the mean values and deviations from three biological replicates and served as the input for the mutant flux estimates.

\begin{tabular}{|c|c|c|c|c|c|}
\hline Strain & SEA-1 & SEA-2A & SEA-2B & SEA-3 & SEA-3 control \\
\hline$\mu\left[h^{-1}\right]$ & $0.26 \pm 0.00$ & $0.23 \pm 0.00$ & $0.25 \pm 0.02$ & $0.30 \pm 0.02$ & $0.24 \pm 0.02$ \\
\hline$q_{\text {Lys }}\left[\mathrm{mmol} \mathrm{g}{ }^{-1} \mathrm{~h}^{-1}\right]$ & $0.55 \pm 0.10$ & $0.67 \pm 0.08$ & $0.72 \pm 0.05$ & $1.08 \pm 0.02$ & $0.69 \pm 0.03$ \\
\hline $\mathrm{q}_{\mathrm{s}}\left[\mathrm{mmol} \mathrm{g} \mathrm{g}^{-1} \mathrm{~h}^{-1}\right]$ & $6.1 \pm 1.1$ & $6.5 \pm 0.4$ & $6.3 \pm 0.4$ & $7.5 \pm 0.6$ & $6.0 \pm 0.3$ \\
\hline $\mathrm{Y}_{\text {Lys } / \mathrm{S}}\left[\mathrm{mmol} \mathrm{mol}{ }^{-1}\right]$ & $90.1 \pm 1.1$ & $102.4 \pm 6.9$ & $113.6 \pm 6.1$ & $144.8 \pm 9.5$ & $113.1 \pm 1.5$ \\
\hline $\mathrm{Y}_{\mathrm{X} / \mathrm{S}}\left[\mathrm{g} \mathrm{mol}^{-1}\right]$ & $40.2 \pm 2.0$ & $35.7 \pm 1.3$ & $39.8 \pm 3.3$ & $40.0 \pm 4.3$ & $39.5 \pm 2.0$ \\
\hline $\mathrm{Y}_{\mathrm{Frc} / \mathrm{S}}\left[\mathrm{mmol} \mathrm{mol}^{-1}\right]$ & $262.1 \pm 14.2$ & $186.4 \pm 12.7$ & $183.9 \pm 13.3$ & $82.2 \pm 18.0$ & $208.3 \pm 18.4$ \\
\hline $\mathrm{Y}_{\mathrm{Lac} / \mathrm{S}}\left[\mathrm{mmol} \mathrm{mol}{ }^{-1}\right]$ & $9.9 \pm 1.0$ & $<0.01$ & $<0.01$ & $<0.01$ & $<0.01$ \\
\hline $\mathrm{Y}_{\mathrm{Glu} / \mathrm{s}}\left[\mathrm{mmol} \mathrm{mol}{ }^{-1}\right]$ & $6.3 \pm 0.3$ & $10.5 \pm 1.6$ & $9.0 \pm 1.0$ & $10.3 \pm 1.2$ & $3.0 \pm 0.1$ \\
\hline $\mathrm{Y}_{\mathrm{Gly} / \mathrm{S}}\left[\mathrm{mmol} \mathrm{mol}{ }^{-1}\right]$ & $2.3 \pm 0.1$ & $4.1 \pm 0.2$ & $4.5 \pm 0.4$ & $6.6 \pm 1.2$ & $3.0 \pm 0.3$ \\
\hline $\mathrm{Y}_{\text {Tre/s }}\left[\mathrm{mmol} \mathrm{mol}{ }^{-1}\right]$ & $2.6 \pm 0.2$ & $3.5 \pm 0.1$ & $3.2 \pm 0.3$ & $3.0 \pm 0.4$ & $3.4 \pm 0.3$ \\
\hline $\mathrm{Y}_{\text {Ace/s }}\left[\mathrm{mmol} \mathrm{mol}{ }^{-1}\right]$ & $1.8 \pm 0.9$ & $<0.01$ & $<0.01$ & $<0.01$ & $<0.01$ \\
\hline $\mathrm{Y}_{\mathrm{Ala} / \mathrm{s}}\left[\mathrm{mmol} \mathrm{mol}^{-1}\right]$ & $0.7 \pm 0.2$ & $<0.01$ & $<0.01$ & $<0.01$ & $<0.01$ \\
\hline
\end{tabular}


Table 3. Lysine production from mannitol using metabolically engineered strains of Corynebacterium glutamicum. The data comprise the mean specific rate of lysine formation ( $\left.q_{L y s}\right)$, the yield of lysine $\left(Y_{\text {Lys } / S}\right)$ and the yield of biomass $\left(\mathrm{Y}_{\mathrm{X} / \mathrm{S}}\right)$. For each strain, the data reflect the entire cultivation period until the mannitol and transiently accumulated fructose had been consumed. The genealogy comprises the strains SEA-1, SEA-2A, SEA-2B, and SEA-3. The data represent the mean values and deviations from three biological replicates.

\begin{tabular}{lcccc}
\hline Strain & SEA-1 & SEA-2A & SEA-2B & SEA-3 \\
& & & & \\
\hline $\mathrm{q}_{\text {Lys }}\left[\mathrm{mmol} \mathrm{g}^{-1} \mathrm{~h}^{-1}\right]$ & $0.73 \pm 0.02$ & $0.78 \pm 0.00$ & $0.91 \pm 0.04$ & $1.27 \pm 0.03$ \\
$\mathrm{Y}_{\text {Lys } / \mathrm{S}}\left[\mathrm{mol} \mathrm{mol}^{-1}\right]$ & $0.15 \pm 0.01$ & $0.17 \pm 0.01$ & $0.20 \pm 0.01$ & $0.24 \pm 0.00$ \\
$\mathrm{Y}_{\mathrm{X} / \mathrm{S}}\left[\mathrm{g} \mathrm{mol}^{-1}\right]$ & $54.3 \pm 2.2$ & $57.3 \pm 5.3$ & $63.1 \pm 0.6$ & $54.7 \pm 4.7$
\end{tabular}




\section{ACCEPTED MANUSCRIPT}

Table 4: Isotopic labelling pattern of proteinogenic alanine in Corynebacterium glutamicum SEA-1, SEA-2B, and SEA-3 grown on different tracer substrates. The summed fractional labeling (SFL $\left.L_{M S}\right)$ obtained via GCMS analysis of the $t$-butyl-dimethylsilyl derivative of alanine at $\mathrm{m} / \mathrm{z}$ of 260 to 263 was corrected for natural isotopes (Table S2). The data represent the mean values with the corresponding deviations from three biological replicates. In addition, the ${ }^{13} \mathrm{C}$ enrichment of the individual carbon atoms of proteinogenic alanine was measured by NMR, which also allowed to infer the summed fractional labeling (SFL $\left.L_{N M R}\right)$.

\begin{tabular}{|c|c|c|c|c|c|c|}
\hline Strain & Substrate & $\mathrm{SFL}_{\mathrm{MS}}[\%]$ & $\mathrm{C}_{1}[\%]$ & $\mathrm{C}_{2}[\%]$ & $\mathrm{C}_{3}[\%]$ & SFLnMR [\%] \\
\hline SEA-1 & $\begin{array}{l}{\left[1-^{13} \mathrm{C}\right]} \\
\text { mannitol }\end{array}$ & $16.6 \pm 0.01$ & $2.3 \pm 0.2$ & & $46.0 \pm 0.1$ & $17.1 \pm 0.4$ \\
\hline SEA-2B & $\begin{array}{l}{\left[1-{ }^{13} \mathrm{C}\right]} \\
\text { mannitol }\end{array}$ & $16.0 \pm 0.01$ & $2.3 \pm 0.1$ & $2.6 \pm 0.1$ & $43.4 \pm 0.1$ & $16.1 \pm 0.3$ \\
\hline SEA-3 & $\begin{array}{l}{\left[1-{ }^{13} \mathrm{C}\right]} \\
\text { mannitol }\end{array}$ & $16.6 \pm 0.01$ & 0 & $2.4 \pm 0.0$ & $44.9 \pm 0.0$ & $16.5 \pm 0.2$ \\
\hline SEA-1 & $\begin{array}{l}{\left[1{ }^{-3} \mathrm{C}\right]} \\
\text { glucose }\end{array}$ & $7.4 \pm 0.00$ & & n.d. & n.d. & n.d. \\
\hline SEA-1 & $\begin{array}{l}{\left[1-{ }^{-3} \mathrm{C}\right]} \\
\text { fructose }\end{array}$ & $16.0 \pm 0.01$ & n.d. & n.d. & n.d. & n.d. \\
\hline
\end{tabular}

n. d. = not determined 


\section{ACCEPTED MANUSCRIPT}

Table 5: Kinetics of two different fructokinases expressed in lysine-producing Corynebacterium glutamicum. The kinetics were derived via model-based fitting of the experimental data (i.e., the specific enzyme activity versus the varied concentrations of fructose and ATP) to the Michaelis-Menten equation. The SEA-2A strain expressed a genomic copy of the scrK gene encoding fructokinase from Streptococcus mutans, and the SEA-2B strain expressed a genomic copy of the mak gene encoding fructokinase from Escherichia coli K12-MG1655. All strains were grown on minimal medium with mannitol as the sole carbon source. The data represent the mean values with the corresponding deviations from three biological replicates.

\begin{tabular}{lccc}
\hline Strain & $\begin{array}{c}\mathbf{K}_{\mathbf{M}, \text { ATP }} \\
(\boldsymbol{\mu M})\end{array}$ & $\begin{array}{c}\mathbf{K}_{\mathbf{M}, \text { Frc }} \\
(\boldsymbol{\mu M})\end{array}$ & $\begin{array}{c}\mathbf{V}_{\max } \\
(\mathbf{m U} / \mathbf{m g})\end{array}$ \\
\hline SEA-1 & n.d. $^{*}$ & n.d. & $<0.01$ \\
SEA-2A & $470 \pm 3$ & $330 \pm 1$ & $108 \pm 1$ \\
SEA-2B & $410 \pm 7$ & $540 \pm 2$ & $161 \pm 1$ \\
\hline
\end{tabular}

*n.d., not determined 


\section{Highlights}

\section{ACCEPTED MANUSCRIPT}

- First cell factory of Corynebacterium glutamicum, producing lysine from mannitol

- Mannitol-grown cells exhibit extremely low oxidative pentose phosphate pathway flux, but high flux through glycolysis and TCA cycle

- Expression of fructokinase and NADPH-coupled glycolysis are key modifications to increase lysine production

- This opens the door to use marine macro algae, third generation renewables with huge mannitol content for lysine production 